\title{
[PRE-PRINT MANUSCRIPT]
}

\section{Understanding Prosocial and Antisocial Behaviours: The Roles of Self- Focused and Other-Focused Motivational Orientations}

\author{
Keven Joyal-Desmarais ${ }^{\mathrm{a}, \mathrm{b} *}$, Hyun Euh $^{\mathrm{c}}$, Alexandra Scharmer ${ }^{\mathrm{c}}$, Mark Snyder $^{\mathrm{c}}$ \\ ${ }^{a}$ Montreal Behavioral Medicine Centre, CIUSSS-NIM, 5400 boul Gouin O, \\ Montreal, Québec, Canada, H4J 1C5 \\ bepartment of Health, Kinesiology, and Applied Physiology, Concordia University, 7141 Sherbrooke \\ Street West, Montreal, Quebec, Canada, H4B 1R6 \\ ${ }^{\mathrm{c}}$ Department of Psychology, University of Minnesota, 75 E River Road, Minneapolis, Minnesota, United \\ States, 55455 \\ *Correspondence concerning this article should be addressed to Keven Joyal-Desmarais \\ (joyal008@umn.edu), Montreal Behavioral Medicine Centre, CIUSSS-NIM, 5400 boul Gouin O, \\ Montreal, Québec, Canada, H4J 1C5.
}

\section{Open Science Statement:}

\section{Author Notes}

A project page for this work can be accessed at osf.io/fwypt. This page contains our supplemental materials and the analysis script files we used for the four studies. Additionally, the page includes the dataset used for Study 4.

\section{Conflict of Interest Statement:}

The authors declare no conflict of interest.

\section{Acknowledgements.}

Research ideas for Studies 1 and 2 were developed by KJD and HE, with contributions from MS. All authors contributed the analysis plan and design for Studies 3 and 4. Data preparation and analyses were conducted by KJD, with assistance from HE and AS. KJD wrote the initial version of the manuscript with support from HE, AS and MS. All authors read and approved the final manuscript.

This research was supported by a Social Sciences and Humanities Research Council (SSHRC) of Canada doctoral fellowship to KJD. Data collection for Study 4 was supported by the Center for the Study of the Individual and Society at the University of Minnesota. The authors did not receive any funds or grant to do this research from funding agencies in the public, commercial, or not-for-profit sectors.

We extend special thanks to Joseph A. Vitriol for his involvement and substantial feedback throughout the project. We acknowledge and thank the World Values Survey's network of dedicated scientists for collecting and making available a significant portion of the data used in the current work. We also acknowledge our use of data from Add Health, a program project designed by J. Richard Udry, Peter S. Bearman, and Kathleen Mullan Harris, and funded by a grant P01-HD31921 from the Eunice Kennedy Shriver National Institute of Child Health and Human Development, with cooperative funding from 17 other agencies. No direct support was received from grant P01-HD31921 for the current analysis. Finally, we would also like to extend our thanks to the participants in each of the four studies reported, and to Mina Joyal-Desmarais and Midori Nishioka for providing support throughout the project.

We acknowledge that the results of Studies 1, 2, and 3, were previously presented at: the 2017 Conference of the Society for the Psychological Study of Social Issues in Albuquerque, New Mexico, USA; the $29^{\text {th }}$ International Congress of Applied Psychology in Montreal, Quebec, Canada, and; the 2019 Annual Convention of the Society for Personality and Social Psychology in Portland, USA. 


\begin{abstract}
We examine how individual differences in self-focused and other-focused orientations relate to prosocial (e.g., helping, volunteerism) and antisocial (e.g., theft, violence) behaviours/attitudes. Using four datasets (total $N=176,216$; across 78 countries), we find that other-focused orientations (e.g., socially focused values, intimacy motivation, compassionate/communal traits) generally relate positively to prosocial outcomes and negatively to antisocial outcomes. These effects are highly consistent cross-nationally and across multiple ways of operationalizing constructs. In contrast, self-focused orientations (e.g., personally focused values, power motivation, assertive/agentic traits) tend to relate positively to both antisocial and prosocial outcomes. However, associations to prosocial outcomes vary substantially across nations and construct operationalizations. Overall, the effects of other-focused orientations are consistently larger than those of self-focused orientations. We discuss the implications of these findings for interventions that target pro-social and anti-social motivations to influence prosocial and antisocial outcomes.
\end{abstract}

Keywords: (1) Prosocial Behaviour; (2) Antisocial Behaviour and Aggression; (3) Self-Focused Orientations; (4) Other-Focused Orientations; (5) Egoistic and Altruistic Motivations; (6) Interpersonal Circumplex 
Understanding Prosocial and Antisocial Behaviours: The Roles of Self-Focused and OtherFocused Motivational Orientations

\section{Introduction}

Fundamental to the concerns of many social scientists are behaviours that benefit others (i.e., prosocial behaviours; Batson \& Powell, 2003; Schroeder \& Graziano, 2015) and behaviours that harm others (i.e., antisocial behaviours; DeWall et al., 2012). Although researchers often consider overlapping causes for prosocial and antisocial behaviours, the literatures on these two types of behaviours have largely operated in isolation from each other. This makes it difficult to determine how variables simultaneously affect both kinds of behaviours. This is an important concern, both theoretically and practically. For example, having observed that social inhibitions impede prosocial acts (e.g., Guo et al., 2018), an interventionist may apply these findings to teach people to overcome their inhibitions. However, lowered inhibitions also promote antisocial behaviours (Hirsh et al., 2011). Thus, such an intervention may increase prosocial behaviours (as intended) but also have the unintended consequence of increasing antisocial behaviours.

To address the dynamics of prosocial and antisocial behaviours within a common theoretical framework, we examine the role of two broad types of motivational variables thought to underlie much interpersonal behaviour: self-focused orientations, which focus on obtaining outcomes for oneself, and other-focused orientations, which focus on building/maintaining relationships and achieving outcomes for others. In developing this framework, we begin by defining each variable and describe how self- and other-focused orientations can each promote and inhibit prosocial and antisocial behaviours. We then argue that the associations between the four variables at a global level should operate in a more generalizable way and present four 
studies to quantify the general associations between the variables.

\subsection{Defining Prosocial and Antisocial Behaviours}

Prosocial behaviours are acts that have positive or beneficial outcomes for others (Dovidio et al., 2006; Eisenberg \& Miller, 1987; Snyder \& Dwyer, 2012), and antisocial behaviours are acts that have negative or harmful outcomes for others (Bandura, 1978; Buss, 1961; Loeber \& Hay, 1997). Both types of behaviours can take many forms.

Prosocial behaviours can be planned or spontaneous (e.g., looking after a person's pet in their absence vs. spontaneously helping a stranger; Amato, 1990; Latané \& Darley, 1968), have direct or indirect benefits for others (e.g., giving money to the homeless vs. engaging in proenvironmental behaviours; De Groot \& Steg, 2009; Rushton et al., 1981), be informal or formal (e.g., comforting a friend vs. formal volunteerism; Omoto \& Snyder, 1995; Walker et al., 1995), and enacted with or without deliberate intentions (e.g., donating blood vs. recycling out of habit; Kurz et al., 2014; Ouellette \& Wood, 1998; Verplanken \& Aarts, 1999).

Antisocial behaviours can also be planned or spontaneous (e.g., playing a debasing prank on someone vs. hitting someone after being insulted; Kempes et al., 2005), direct or indirect (e.g., physically hitting someone vs. spreading rumours; Card et al., 2008), legal or illegal (e.g., acting rudely vs. stealing something; Anderson, 1987; Porath \& Erez, 2007), and active or passive (e.g., lying to someone vs. withholding information from someone; Buller \& Burgoon, 1996; Connelly et al., 2012). Many antisocial acts are forms of aggression, which involves explicit intention to harm another (Anderson \& Bushman, 2002; DeWall et al., 2012). However, antisocial behaviours can also occur without explicit intentions, such as through reflexive acts (e.g., automatically engaging in harmful behaviour without realizing it; Todorov \& Bargh, 2002) and antisocial negligence (e.g., harming others due to a lack of regard for them, rather than 
intending to; Albert \& Thilagavathy, 2013; Mills et al., 2004; Swanson et al., 1994).

Table 1.

Definitions of Prosocial and Antisocial Behaviours

Concept Definition Examples

\begin{tabular}{lll}
\hline Prosocial & Behaviours which increase positive/beneficial & - Emotional support \\
Behaviours & (or decrease negative/harmful) outcomes for & - Volunteerism \\
& others. Outcomes can be material, physical, & - Donating blood/organs \\
& psychological, tangible, or intangible. & - Donating to charities \\
& $\begin{array}{l}\text { Prosocial behaviours generally include acts } \\
\text { that are supportive of others' goals/wants. }\end{array}$ & - Doing favours for others \\
\hline Antisocial & Behaviours which increase negative/harmful & - Physical violence \\
Behaviours & (or decrease positive/beneficial) outcomes for & - Verbal/social aggression \\
& others. Outcomes can be material, physical, & - Theft \\
& psychological, tangible, or intangible. & - Sabotaging other's work \\
& $\begin{array}{l}\text { Antisocial behaviours generally include acts } \\
\text { that are against (or interfere with) others' }\end{array}$ & - Damaging other's property \\
& goals/wants. & \\
\hline
\end{tabular}

Table 1 provides elaborated definitions for prosocial and antisocial behaviours that capture the breadth of examples we have given. Although prosocial and antisocial behaviours have sometimes been discussed as conceptual opposites (Batson, 1998; Gomà-i-Freixanet, 1995; Krueger et al., 2001; Wispé, 1972) we define them separately as evidence indicates they should be treated as distinct behavioural dimensions. For instance, factor analytic work shows that prosocial and antisocial behaviours are distinct (Harris et al., 1996; Krueger et al., 2001), and the typical association between these behaviours has neither been large (e.g., Eron \& Huesmann, 1984; Dalal, 2005), nor consistent (sometimes even positive: Card et al., 2008; Duncan et al., 2002). Moreover, certain behaviours have both prosocial and antisocial elements (e.g., extreme political activism can help one group while harming another; Long \& Burke, 2015).

Consequently, our definitions ensure that the core features of each behaviour (e.g., prosocial behaviours providing benefits to someone) do not preclude features of the other (e.g., bringing harm to others), allowing any given behaviour to be conceived along both dimensions. However, 
we acknowledge that other definitions exist (e.g., DeWall et al., 2012; Eisenberg \& Miller, 1987), and the Appendix provides further considerations that informed our definitions.

\subsection{Exploring the Common and Distinct Etiologies of Prosocial and Antisocial Behaviours}

Because prosocial and antisocial behaviours are distinct dimensions, variables that predict them can follow several patterns of associations, each with unique practical implications.

First, some variables predict prosocial behaviours, but not antisocial behaviours. For example, extraversion positively predicts volunteerism (Carlo et al., 2005), but is unrelated or weakly related to antisocial behaviours (Jones et al., 2011; Miller \& Lynam, 2001). Targeting such variables (e.g., creating situations to elicit extraverted states; Fleeson et al., 2002;

Rauthmann et al., 2014) could be useful to obtain desired effects of increasing prosocial behaviours, while being safe to avoid undesired consequences (increasing antisocial behaviours).

Second, some variables predict antisocial behaviours, but have negligible associations with prosocial behaviours. For instance, anger and negative affectivity are well-known predictors of aggression (DeWall et al., 2012; Hershcovis et al., 2007), but have much weaker associations with prosocial behaviours (e.g., Krueger et al., 2001; Organ \& Ryan, 1995). Such variables should also generally be useful and safe targets - this time to decrease antisocial behaviours.

Third, some variables predict prosocial and antisocial behaviours in opposite directions.

For example, self-control, empathy, and agreeableness are typically positively related to prosocial behaviours (DeWall et al., 2008; Eisenberg \& Miller, 1987; Habashi et al., 2016), but negatively related to antisocial behaviours (Denson et al., 2012; Jolliffe \& Farrington, 2004; Vize et al., 2018). Such variables represent ideal targets for interventions by simultaneously increasing prosocial behaviours and decreasing antisocial behaviours.

Fourth, some variables predict prosocial and antisocial behaviours in the same direction. 
For instance, disinhibition can increase both prosocial and antisocial behaviours (Guo et al., 2018; Hirsh et al., 2011), and so can threats to self-evaluations (Felson, 1978; Griskevicius et al., 2010; McAndrew, 2002). Although targeting such variables can have benefits, it can also lead to undesirable effects. For instance, an intervention that increases prosocial behaviours by reducing social inhibitions could inadvertently increase antisocial acts.

Given the above, the current project aims to examine which patterns best capture two variables that have long been proposed as key predictors of social behaviours: self- and otherfocused orientations.

\subsection{Self-Focused and Other-Focused Orientations: A Dominant Division of Motivational Orientations in Psychology}

One of the most common distinctions made in theories of personality and motivation is that between self- and other-focused orientations. Broadly, self-focused orientations are a class of variables that reflect dispositions to seek beneficial outcomes for oneself, whereas otherfocused orientations are a class of variables that reflect dispositions to seek beneficial outcomes for others and/or to build and maintain social relationships (see Table 2 for more specific definitions; for similar definitions see also: Abele \& Wojciszke, 2007; Miyamoto et al., 2018). This fundamental dichotomy can be found in diverse frameworks on personality traits, motivations, goals, needs, and values. Notable frameworks include: the Interpersonal Circumplex tradition, which distinguishes between the dimensions of agency vs. communion (Abele \& Wojciszke, 2007; Trapnell \& Wiggins, 1990), frameworks of human values that distinguish between personal/individual focus values vs. social/collective focus values (Mueller \& Wornhoff, 1990; Schwartz et al., 2012b), models of cultural differences that distinguish between individualistic/independent vs. collectivistic/interdependent orientations (Hui \& Triandis, 1986; 
Markus \& Kitayama, 1991), and more (e.g., Abele \& Wojciszke, 2014; Chulef et al., 2001; De

Dreu \& Nauta, 2009; Gerbasi \& Prentice, 2013; Wicker et al., 1984). Table 2 provides and

defines six frameworks representative of this dichotomy that we examine in our studies.

Table 2.

Definitions and Synthesis of Self-Focused and Other-Focused Orientations

\section{Core Definitions for Self-Focused and Other-Focused Orientations}

Self-Focused Orientations: Orientations describing the degree to which a person focuses on, pays attention to, and seeks out outcomes that benefit them personally, or seeks to increase their own personal agency/control over such personal outcomes.

Other-Focused Orientations: Orientations describing the degree to which a person focuses on, pays attention to, and seeks out outcomes for the benefit of others, to build and maintain relationships with others, or to support others' goals/wants.

Example Frameworks Distinguishing Self-Focused and Other-Focused Orientations

1. Interpersonal Circumplex: A widely used framework for organizing interpersonal space (covering elements such as people's behaviours, traits, goals, motivations, values, needs) according to two central dimensions.

a. Agency: Interpersonal dimension concerned with differentiating and promoting outcomes for the self through themes such as power and mastery. The dimension of agency is sometimes referred to using other labels such as dominance and assertiveness.

b. Communion: Interpersonal dimension concerned with creating and maintaining connections with others, such as through agreeable and caring behaviours. The dimension of communion is sometimes referred to using other labels such as nurturance, affiliation, and warmth.

References: Abele \& Wojciszke, 2007; 2014; Bakan, 1966; Freedman et al., 1951; Gurtman, 2009; Hiller \& Philiber, 1985; Leary, 1957; Leonard, 1997; Locke, 2000; Trapnell \& Wiggins, 1990; Wiggins, 1996; Wiggins \& Holzmuller, 1981.

2. Schwartz' Theory of Basic Human Values: An influential framework for understanding human values. Distinguishes between 19 values, which are organized along a circular continuum is defined by the presence of higher order values. At the highest level, each value can be organized according to whether it has a social focus or personal focus.

a. Personal Focus Values: Values that concern outcomes for the self. Subsumes selfenhancement values, which focus on directly pursuing one's own interests, and openness to change values, which focus on gaining exposure to new experiences, ideas, and skills.

b. Social Focus Values: Values that concern outcomes for others and for how one relates to others. Subsumes self-transcendence values, which focus on concerns for the welfare of others, and conservation values, which focus on maintaining social order and avoiding social disruption/change.

References: Rudnev et al., 2018; Schwartz, 1994a; 2012; Schwartz et al., 2012b; Schwartz \& Boehnke, 2004.

3. Masculinity and femininity (as captured in scales like the BSRI): Personality traits perceived as differentially desirable for men and women. ${ }^{1}$ Distinction between the two 
trait dimensions draws heavily from the two axes of the interpersonal circumplex.

a. Masculinity: A general orientation tied to themes of instrumentality, assertiveness, power, and independence.

b. Femininity: A general orientation tied to themes of expressiveness, nurturance, and communality, along with a general concern for others.

References: Bakan, 1966; Bem, 1974; Bem et al., 1976; Heilbrun \& Bailey, 1986; Lippa, 2001; Wood \& Eagly, 2015.

4. Independent vs. Interdependent Self-Construal: Individual differences in how people construe their sense of self, along with their relationship to the world around them. Frequently understood as an individual-level manifestation of group-based differences in individualistic/collectivistic cultural values.

a. Independent Self-Construal: Degree to which people construe their sense of self as highly individualized and independent from others. People high in independent self-construal value independence and act in ways to express/strengthen it. Tied to constructs such as individualism, egocentrism, and idiocentrism.

b. Interdependent Self-Construal: Degree to which people construe their sense of self as interconnected with others around them. People high in interdependent self-construal value relationship maintenance and acting in accordance to established norms. Tied to constructs such as collectivism, sociocentrism, and allocentrism

References: Hofstede, 1980; 2011; Hui \& Triandis, 1986; Kitayama et al., 2019; Markus \& Kitayama, 1991; Singelis, 1994; Triandis, 1995; 2001.

5. Self- and Other-Interest: Individual difference measure of the extent to which people are motivated to act in their own self-interest, or in the interest of others.

a. Self-Interest: Orientation towards the pursuit of personal gains in socially valued domains such as achieving social status/power, happiness, and occupational success.

b. Other-Interest: Orientation towards the pursuit of gains for others in socially valued domains (e.g., social status/power, happiness, and occupational success).

References: Gerbasi, 2011; Gerbasi \& Prentice, 2013.

6. Power and Achievement vs. Affiliation and Intimacy Motives: Four highly studied motivational dimensions tied to basic psychological needs. Frequently discussed in relation to the interpersonal circumplex and captured by similar values in Schwartz's model.

a. Power and Achievement: Power is the motive for having personal influence over others, along with personal success and status, whereas achievement is the motive for learning and mastering tasks, along with achieving excellent work.

b. Affiliation and Intimacy: Affiliation is the motive for building and maintaining friendly relationships with others in general, whereas intimacy is the motive for forming profound relationships with close others and engaging in behaviours such as self-disclosures and meaningful mutual exchange.

References: Brunstein et al., 1998; Heckhausen \& Heckhausen, 2008; Mansfield \& McAdams, 1996; McAdams \& Constantian, 1983; Schönbrodt \& Gerstenberg, 2012; Sokolowski, 2008; Sokolowski et al., 2000; Winter, 1991; Winter et al., 1998.

${ }^{1}$ Although masculinity/femininity continue to correspond closely to the agency/communion distinction, the usefulness of the dimensions to represent gender-normative traits has been criticized as gender roles and tendencies have deviated from a close correspondence to the two dimensions (e.g., Auster \& Ohm, 2000; Donnelly \& Twenge, 2017; Twenge, 1997). 
Although important differences exist between these frameworks, each contrasts dimensions that focus on individuals being motivated to obtain personal outcomes — with a consistency in themes such as self-expression, power, stimulation, and mastery - to dimensions that focus on interpersonal others - with a consistency in themes of caring for others, and acting in ways that promote/maintain social relationships and ingroup harmony. The striking similarity between these frameworks has been noted by many researchers and is so pronounced that measures and constructs are frequently repurposed between the frameworks (e.g., Abele \& Wojciszke, 2014; Buchanan \& Bardi, 2015; Frimer et al., 2011; Helgeseon, 1994; Locke, 2000; Miyamoto et al., 2018; Oishi et al., 1998; Ponikiewska et al., 2020; Trapnell \& Paulhus, 2012; Verplanken et al., 2009; Wood \& Eagly, 2015). Table A1 of the appendix list works that discuss and document ties between each framework in Table 2.

Most theories view self- and other-focused orientations as distinct dimensions, and empirical findings support this view (e.g., De Dreu \& Nauta, 2009; Markus \& Kitayama, 1991; Trapnell \& Wiggins, 1990; but see Meglino \& Korsgaard, 2004). Although early research frequently described the two dimensions as either independent or opposing, several works have since posited theoretical reasons to expect them to be positively related, and often supportive and mutually reinforcing (Heilbrun \& Bailey, 1986; Leonard, 1997). For example, fostering close relationships with others can be the first step to receiving support from them (Kitayama et al., 2010), and the development of an internalized sense of self-compassion can help one develop compassion towards others (Neff \& Pommier, 2013). There are also cases when self-focused and other-focused orientations directly lead people to pursue similar endpoints. For example, both collectivism (other-focused) and performance/status motives (self-focused) can lead young adults to pursue prestigious employment (e.g., Fouad et al., 2008; Haase \& LautenschlaGer, 
2011). For other-focused individuals, this pursuit may arise from wishing to meet the expectations of others (e.g., parents; Fouad et al., 2008), whereas for self-focused individuals, the goal is to achieve prestige; however, what is considered prestigious and successful is still defined by broader social norms (Gerbasi \& Prentice, 2013).

In addition to these perspectives, a positive association between self-focused and otherfocused orientations could also emerge as the result of a general motivational factor, reflecting a disposition to act in goal-directed ways. For instance, some individuals are chronically motivated to act to fulfil their motivations, but others may find themselves in chronic states of amotivation/apathy (Husain \& Roiser, 2018). Such a general factor has been described by researchers in several areas, spanning both the motives and values literatures (Batey et al., 2011; Borg \& Bardi, 2016; Gunnell \& Gaudreau, 2015). For example, Borg \& Bardi (2016) posit a "value-guidedness" factor underlying human values, representing a general disposition to act in pursuit of one's values.

Theoretical positions that self-focused and other-focused orientations should be positively correlated also hold empirical grounds. Studies have frequently found measures of self-focused (e.g., agency, personal focus values, independence) and other-focused (e.g., communion, social focus values, interdependence) orientations to be correlated between $r=0$ and 0.5 , with the magnitude of that correlation depending on the specific construct evaluated (e.g., Abele \& Wojciszke, 2007; Datu, 2015; DeYoung et al., 2007; 2013; Gerbasi \& Prentice, 2013; Heilbrun \& Bailey, 1986; Howell \& Buro, 2017; Joyal-Desmarais et al., 2020; Schwartz \& Boehnke, 2004; Singelis, 1994; Trapnell \& Paulhus, 2012; Wang \& Wang, 2016; Ward et al., 2006; Weisberg et al., 2011). Taking these findings into account, we expect that the true average correlation between the two dimensions is likely located in the middle of the above range 
(moderate and positive).

\subsection{How Do Self-Focused and Other-Focused Orientations Relate to Prosocial and Antisocial Behaviours?}

In the literature on prosocial behaviours, there has long been debate about whether people engage in prosocial acts predominantly for altruistic (other-focused) or selfish (selffocused) reasons (Batson 1987; Schaller \& Cialdini, 1988; Rothstein \& Pierotti, 1988; Schroeder et al., 1988). Over the years, studies have indicated that people can and do engage in prosocial behaviours for both types of reasons (Snyder \& Dwyer, 2012). For example, research on volunteerism (Carpenter \& Myers, 2010; Clary et al., 1998) shows that people commonly volunteer for both self-oriented reasons (e.g., to improve one's career prospects or reputation) and other-oriented reasons (e.g., to fulfil humanitarian values or conform with social norms). Interventions have also successfully leveraged both types of reasons to encourage prosocial behaviour (e.g., Clary \& Snyder, 1999, Simpson \& Willer, 2008).

However, the relative importance of the two types of motivations remains unclear. Additionally, research has mostly examined whether these motivational factors can promote specific prosocial behaviours (e.g., volunteerism), rather than prosocial behaviours in general. This is an important omission, as although each type of motivational orientation can be leveraged to promote a given prosocial behaviour, it is also possible for them to lower other forms of prosocial behaviours. For example, self-focused reasons can lead to more helping (e.g., to feel better about oneself; Clary \& Snyder, 1999) or less helping (to protect personal resources; JoyalDesmarais et al., 2018). Therefore, a global perspective on how the two types of motivational orientations relate to prosocial behaviours is warranted.

There is also substantial evidence that people can engage in or refrain from antisocial 
behaviours for either self- or other-focused reasons (Baron, 1971; Baumeister et al., 1996; Borden \& Taylor, 1973; Halevy et al., 2008; Lambe et al., 2018; Nagin \& Pogarsky, 2003; Wispé, 1972). For instance, a person may harm someone to re-establish a positive self-image following an insult (Lambe et al., 2018), or to express power-related motivations (Adams et al., 1995; Henry et al., 2005)—both self-focused reasons. However, a person can also harm others for other-focused reasons, such as to protect others (Böhm et al., 2016), to further a social cause (Long \& Burke, 2015), to fulfil someone's request (Borden \& Taylor, 1973), or to enforce/impose a group's social norms (Chowdhry, 1997; Faragó et al., 2019). Certain selffocused and other-focused orientations have shown specific relations with specific types of antisocial behaviours. For example, self-enhancement values (self-focused) generally positively predict aggression, whereas self-transcendence values (other-focused) inhibit it (BenishWeisman 2015; 2019). However, as with prosocial behaviour research, the overall associations between self-focused orientation, other-focused orientations, and antisocial behaviours are not fully documented.

Although self- and other-focused orientations can each motivate or inhibit prosocial and antisocial behaviours (e.g., depending on contextual factors), the overall associations between these variables should operate in systematic ways. One important factor in determining the strength and direction of each association may be the degree to which a type of behaviour serves either as ends or means to achieve motivational goals. A behaviour is an end if it is intrinsically tied to the central goals of a motivational orientation. In this way, just as eating inherently serves to fulfil hunger needs, engaging in prosocial behaviours (e.g., helping a neighbour) and inhibiting antisocial behaviours (e.g., restraining oneself from verbal aggression) each directly serve other-focused goals such as: increasing positive outcomes for others, decreasing harmful 
outcomes for others, or building/maintaining relationships. Generally, we can expect that behaviours would show strong associations to the motivations they inherently fulfil or express (see Bardi \& Schwartz, 2003, or Kruglanski et al., 2018, for similar rationales). Thus, individuals who have greater other-focused orientations should engage in substantially more frequent prosocial behaviours and fewer antisocial behaviours. For example, those with strong communal tendencies (concerned with building/maintaining relationships and caring for others) and those with strong universalism values (concerns for the welfare of all people) should show strong tendencies towards helping and cooperating with others, and against harming others.

In contrast, individuals can also engage in behaviours as means to achieve goals that are not inherent to the behaviours. For instance, many individuals work, not because work is inherently enjoyable, but because a salary can support other goals (e.g., buying food to sustain oneself). Similarly, a highly self-focused person can engage in prosocial or antisocial behaviours not for the inherent impacts on others, but to serve their own benefits (e.g., improve one's reputation via public prosocial acts; Carpenter \& Myers, 2010). If self-serving outcomes can readily be attained from many prosocial and antisocial behaviours — an assertion many interventions depend on (e.g., Clary \& Snyder, 1999; Simpson \& Willer, 2008)—then people with strong self-focused orientations should be attuned to these possibilities and ready to profit from them. For instance, they may readily act on obvious opportunities (e.g., theft of unattended valuables) or be motivated to reshape them to their favour (e.g., request public recognition prior to accepting to donate). Such individuals may focus their attention mostly on how prosocial/antisocial behaviours serve self-focused goals (Derryberry \& Tucker, 1994; Dijksterhuis \& Aarts, 2010), and may overlook the inherent impacts of these behaviours on others, which emerge as by-products of their self-focused pursuits (Rothstein \& Pierotti, 1988). 
In contrast, those with weak self-focused orientations may lack the motivation to attend to and exploit prosocial or antisocial behaviours in the same way. If so, these dynamics should generate positive associations between self-focused orientations and both prosocial and antisocial behaviours. However, because prosocial and antisocial behaviours do not always afford selffocused outcomes, the associations between the behaviours and self-focused orientations should be weaker than those between the behaviours and other-focused orientations.

\subsection{Hypotheses and Current Research}

All in all, the theoretical discussions above allow us to propose a series of hypotheses about the general impact of self-focused and other-focused orientations on prosocial and antisocial behaviours. First, we expect self-focused orientations to be a positive predictor of the two behaviours:

H1: Self-focused orientations should have a positive association with antisocial behaviours, independent of the effect of other-focused orientations

H2: Self-focused orientations should have a positive association with prosocial behaviours, independent of the effect of other-focused orientations

Second, we expect other-focused orientations to predict the two behaviours in opposite directions:

H3: Other-focused orientations should have a negative association with antisocial behaviours, independent of the effect of self-focused orientations

H4: Other-focused orientations should have a positive association with prosocial behaviours, independent of the effect of self-focused orientations

Hypotheses $\mathrm{H}_{1}-\mathrm{H}_{4}$ are represented in Figure 1. 


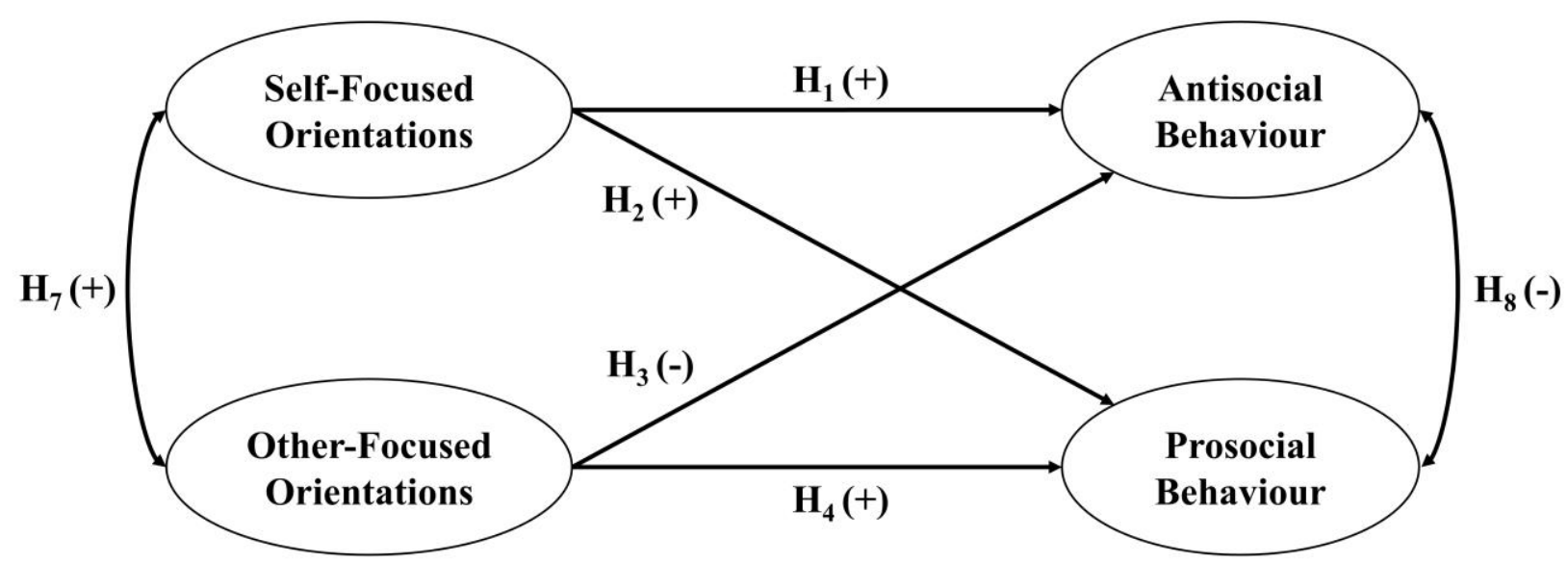

Figure 1. Our general model and predictions (direction of prediction for each predictive pathway is indicated in parentheses).

In addition to the primary hypotheses above, we also conduct exploratory analyses to examine how $\mathrm{H}_{1}-\mathrm{H}_{4}$ vary according to:

(1) the populations from which we draw our samples (Studies $2 \& 3$ will examine our hypotheses cross-nationally);

(2) the ways in which the variables are operationalized (Study 4 will sample several operationalizations of each construct)

Finally, we also posit secondary hypotheses. First, because prosocial/antisocial behaviours are usually ends for achieving other-focused goals, but not self-focused goals:

H5: Other-focused orientations should have a stronger association with antisocial behaviours than should self-focused orientations

H6: Other-focused orientations should have a stronger association with prosocial behaviours than should self-focused orientations

Consistent with past empirical findings, we also make the following predictions about the correlations between our variables: 
H7: Self-focused and other-focused orientations should have a moderate positive association (e.g., $r$ around .3)

H8: Antisocial and prosocial behaviours should have a small-to-moderate negative association. (e.g., $r$ below 0 , but above -.5 )

We examine these hypotheses and questions in four studies. Analyses were conducted using $R$ (R Core team, 2017). Analysis scripts and full survey materials, including all measures we used, are available online (see supplemental materials and project page at: osf.io/fwypt). All data are also available (details are provided in each study descriptions).

Finally, we note that our research predominantly concerns how self- and other-focused orientations are each associated with prosocial and antisocial behaviours when controlling for the other orientation (except $\mathrm{H}_{7}$ and $\mathrm{H}_{8}$ ). This approach was chosen as the frequently observed association between self- and other-focused orientations can create a confounding effect when evaluating how each orientation predicts behaviours. However, because bivariate associations still provide important information, we present them in our supplemental materials (see Tables S3, S8, S27 and S28). Bivariate findings are largely in line with the multivariate analyses presented in text and are not discussed further.

\section{Study 1}

The goal of Study 1 was to examine how self- and other-focused orientations relate to prosocial and antisocial behaviours. To do this, we conducted secondary analyses using the National Longitudinal Study of Adolescent to Adult Health (Add Health; Harris et al., 2009). Add Health is a longitudinal study that began following a nationally representative sample of American grade 7-12 adolescents in 1994-95 (Wave I of Add Health) to understand health and achievement outcomes. Extensive information on the Add Health procedures are available online 
(Harris et al., 2009).

\subsection{Our Sample}

Our analyses use the Wave III Public In-Home Questionnaire portion of the Add Health data (conducted in 2001-2002), which was the only wave that contained necessary items to formulate composite measures of each of our constructs of interest. The data were obtained from the www.icpsr.umich.edu website on October 29, 2015 (Harris \& Udry, 2014). We included all participants who completed at least one of 14 items identified as indicators of self- and otherfocused orientations. This criterion was chosen because only a subset of participants was assigned items to measure self-focused and other-focused orientations. In total, we analysed responses from 1,319 participants. The sample is predominantly female $(61.3 \%)$ and White $(70.8 \%)$, with a mean age of 22 years $(S D=1.8)$. Additional Study 1 demographics are available in the supplemental materials (Table S1).

\subsection{Measures}

All items used to operationalize Study 1 variables are presented in Table S2 of the supplemental materials and descriptive statistics for each measure are in Table S3.

\subsubsection{Self-focused and other-focused orientations.}

We assessed self- and other-focused orientations using a subset of items from the 30-item short form BEM Sex-Role Inventory (BSRI; Bem, 1981). The BSRI consists of statements describing a person and asks participants to indicate on a seven-point scale the degree to which each statement describes them $(1=$ "never or almost never true"; $7=$ "always or almost always true"). The BSRI was originally developed to measure normative masculine, feminine, and neutral personality traits. However, in conceiving these dimensions, Bem drew heavily from ideas that are central the interpersonal circumplex tradition (Bakan, 1966; Bem et al., 1976). As a 
consequence, the masculine dimension bears close correspondence to the self-focused orientation of agency (e.g., pursuit of personal benefits; increasing one's control over personal outcomes), whereas the feminine dimension bears close correspondence to the other-focused orientation of communion (e.g., creating/maintaining relationships, caring for and nurturing others). The correspondence is substantial enough that a consensus exists in the literature that the masculine scale and feminine scale are reliable and valid measures of agency and communion, respectively (Helgeson, 1994; Hiller \& Philiber, 1985; Lippa, 2001; Locke, 2000; Saragovi et al., 1997; Wiggins \& Holzmuller, 1981; Ward et al., 2006; Wood \& Eagly, 2015).

Given the above, we measured participants' self-focused orientation using six items from the masculine subscale that reflect ideas of personal agency (e.g., "I defend my own beliefs"; "I am independent") and participants' other-focused orientation using eight items from the feminine subscale that express a general orientation towards others (e.g., "I am affectionate"; "I am understanding"). In selecting items, we omitted those that referred explicitly to prosocial/antisocial behavioural tendencies (e.g., "I am aggressive"). However, inferences remain unchanged if we used the full BSRI (i.e., significant pathways remain significant in the same direction; see Figure S1 and Section 4 of the supplemental materials).

A confirmatory factor analysis (CFA) was conducted to examine the factor structure of the scales using the lavaan package (Rosseel, 2012). Each item loaded significantly $(p<.01)$ onto its respective factor at a value of or greater than .40 (see Figure S2 of the supplemental file for full CFA results). Further, the standardized reliability alphas $\left(\alpha_{\mathrm{s}}\right)$ were acceptable for both other-focused $\left(\alpha_{\mathrm{s}}=.91\right)$ and self-focused $\left(\alpha_{\mathrm{s}}=.77\right)$ orientation scales.

\subsubsection{Prosocial and antisocial behaviours.}

We used three "yes" or "no" items to assess prosocial behaviours. Two items asked 
participants whether, in the past 12 months, they had (1) performed volunteer/community service work, and (2) donated blood, plasma, or platelets. The third item asked participants whether they were registered organ donors. These items have previously been used in studies of prosocial behaviour (e.g., Konrath \& Handy, 2020).

Ten items asked about antisocial behaviours participants had enacted in the 12 months preceding the survey. Seven items inquired about the frequencies of various behaviours (e.g., theft, property damage) on four-point scales ( $1=$ "Never"; 2 = "1 1 or 2 times"; 3 = "3 or 4 times"; $4=$ "5 or more times"). Two items asked whether participants had ("yes"/"no") pulled a knife/gun on someone or stabbed someone, and a final item asked how many times participants had seriously physically injured someone (coded from $1=$ Never; $6=5$ or more times). These items have previously been used in studies of antisocial behaviour (e.g., Barnes \& Boutwell, 2013; Beaver et al., 2012; Grotevant et al., 2006; Guo et al., 2007). Despite the seriousness of these behaviours, 217 participants had engaged in at least one.

A CFA indicated that each item loaded significantly onto its respective factor $(p<.01)$, although not always at a level of .40 (see Figure S3 of the supplemental file). Reliability was relatively low for prosocial behaviours $\left(\alpha_{\mathrm{s}}=.37\right)$, but decent for antisocial behaviours $\left(\alpha_{\mathrm{s}}=.75\right)$.

\subsection{Analyses and Results}

To examine our hypotheses, we fit a structural equation model (SEM) in lavaan (Rosseel, 2012) using full information maximum likelihood (FIML) to handle missing data. The structure of the model was specified according to Figure 1, and latent variables were modelled according to figures $\mathrm{S} 2$ and $\mathrm{S} 3$ of the supplemental materials. A correlation matrix between all Study 1 items is available in the supplemental materials (Table S4). Table 3 presents the standardized path coefficients, standard errors, confidence intervals (CIs), and $p$-values for the 
SEM model. We found that a higher self-focused orientation was significantly positively associated with antisocial behaviours $\left(\mathrm{H}_{1}\right)$ and prosocial behaviours $\left(\mathrm{H}_{2}\right)$. A higher other-focused orientation was significantly and negatively associated with antisocial behaviours $\left(\mathrm{H}_{3}\right)$ and had a non-significant but positive association with prosocial behaviours $\left(\mathrm{H}_{4}\right)$. These four pathways overlapped in their CIs $\left(\mathrm{H}_{5}, \mathrm{H}_{6}\right)$. Lastly, self-focused and other-focused orientations were correlated at $.59\left(\mathrm{H}_{7}\right)$, and prosocial and antisocial behaviours were correlated at $.08\left(\mathrm{H}_{8}\right)$.

Table 3.

Standardized results from Study 1 structural equation model

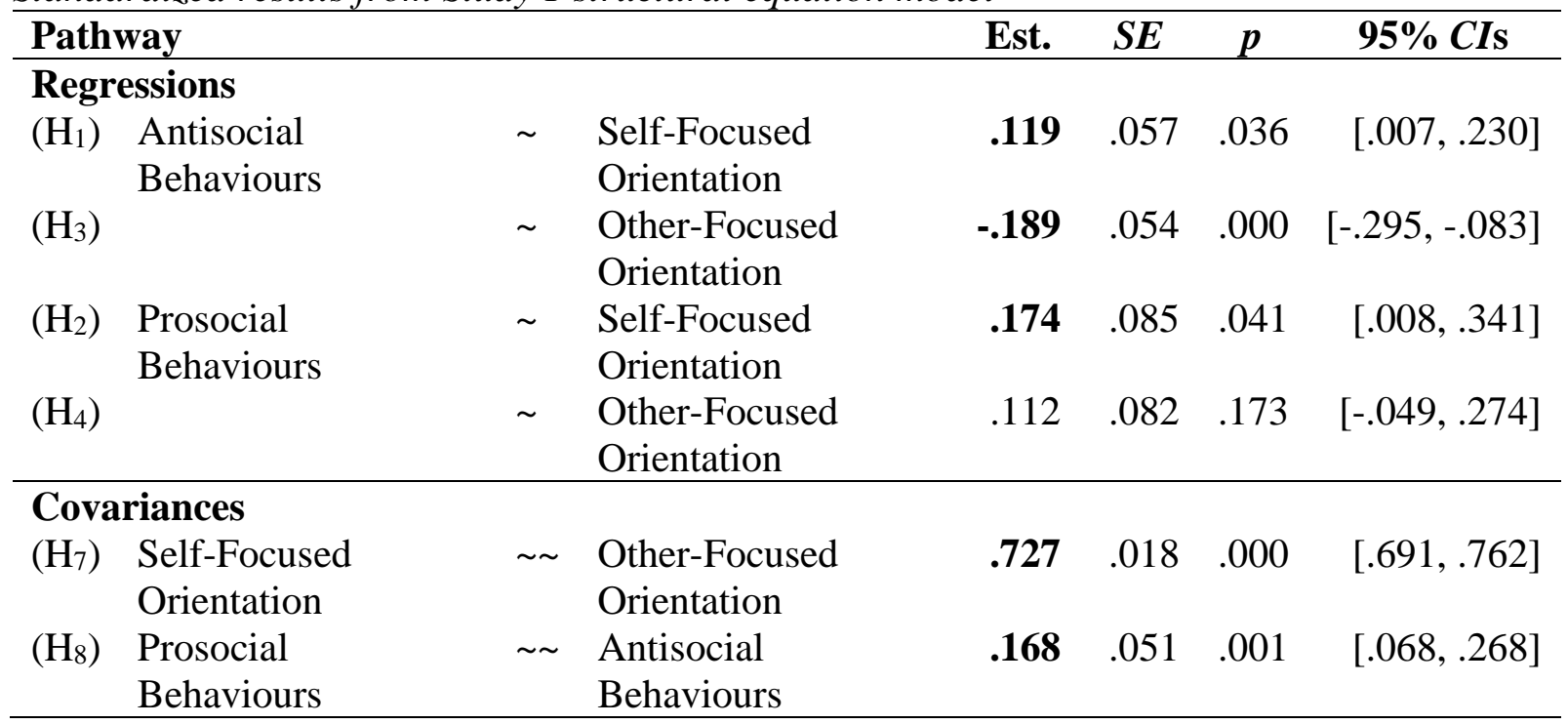

Note. Fit Indices: $\mathrm{CFI}=.851 ; \mathrm{RMSEA}=.064[.061, .067] ;$ SRMR $=.053$. Coefficients in bold font are significant at $p<.05$.

Est. $=$ Standardized parameter estimates; $S E=$ Standard Error $p=p$ value; $C I \mathrm{~s}=95 \%$ Confidence Intervals.

\subsection{Discussion}

Study 1 offers initial evidence for our primary hypotheses. Specifically, self-focused orientations were positively associated with both antisocial and prosocial behaviours (supporting $\mathrm{H}_{1}$ and $\mathrm{H}_{2}$ ) and other-focused orientations were negatively associated with antisocial behaviours (supporting $\mathrm{H}_{3}$ ). However, although the association between other-focused orientation and prosocial behaviours was positive, it was non-significant (not supporting $\mathrm{H}_{4}$ ). Each of the four 
pathways had standardized coefficients between .10 to .20 .

In terms of our secondary hypotheses, we found less support. Although the association between self-focused orientation and antisocial behaviour was smaller in magnitude than the association between other-focused orientation and antisocial behaviour, this difference was not significant (not supporting $\mathrm{H}_{5}$ ). Similarly, the associations between each motivational orientation and prosocial behaviours also showed overlap in size (not supporting $\mathrm{H}_{6}$ ). Although these findings contrast with our hypotheses, we note that Study 1 was likely underpowered to evaluate $\mathrm{H}_{5}$ and $\mathrm{H}_{6}$, as is evidenced by the large CIs produced. Consequently, the following studies used a combination of larger samples (Studies 2 and 3) and better measurement (Study 4) to obtain more precise estimates.

Lastly, we found that our measures of self- and other-focused orientations were more highly correlated than anticipated by $\mathrm{H}_{7}$, and that the correlation between the prosocial and antisocial behaviour measures was significant and positive, albeit small, rather than negative (contrasting with $\mathrm{H}_{8}$ ). Although this last finding deviates from $\mathrm{H}_{8}$, the small positive effect is not incompatible with our framework and could have emerged for several reasons. For instance, it is possible that the association arose due to sampling error, or that another factor is leading these behaviours to be positively correlated. For instance, young adults' opportunities to behave prosocially or antisocially are each constrained by the degree to which they are socially active. However, given that the findings of Study 1 represent only a single test of our hypotheses, we urge caution in evaluating them in isolation.

\section{Studies 2 and 3}

Although Study 1 provides support for several of our primary hypotheses, the study had several limitations. The sampling frame was quite focused - consisting entirely of young, 
predominantly white and female, Americans - and our measures were not optimal. We used indicators of prosocial behaviours with a relatively low reliability, and measures of self- and other-focused orientations that were highly correlated with one another. This could have led to attenuation effects. Finally, we were only able to use a single operationalization of each of our variables of interest, limiting the generalizability of our findings. In our next two studies, we used larger and more diverse samples, and considered alternative measures for each construct.

\subsection{The World Values Survey (WVS)}

To substantially increase the diversity of our sample, we made use of data from the World Values Survey (WVS). The WVS is a large-scale cross-national collaboration, which collects nationally representative surveys around the globe to assess how values and beliefs impact behaviours. For our purposes, we used Wave 5 and Wave 6 of the WVS (Inglehart et al., 2014a; 2014b). Although each wave surveys a different sample of participants, they share similar methodologies. Consequently, we discuss them together. The data were downloaded on May 30, 2017 from www.worldvaluessurvey.org (where additional information on the WVS methodology can be found).

Wave 5 contains data from 83,975 participants $(52 \%$ female; mean age $=41.46, S D=$ 16.49) across 58 countries, and was collected over the years 2005-2009. Wave 6 was collected between 2010-2014 and contains responses from 90,350 participants $(52 \%$ female; mean age $=$ 42.05, $S D=16.48)$ across 60 countries. The samples are diverse across many characteristics, including education and socioeconomic status. See Table S6 of the supplemental materials for detailed demographic analyses for Studies 2-3.

\subsection{Measures}

All items used to operationalize Study 2 and Study 3 variables are presented in Table S7 
of the supplemental materials. Descriptive statistics for each measure are in Table S8.

\subsubsection{Self- and other-focused orientations.}

To assess motivational orientations, we used the set of items included in each wave of the WVS to assess constructs from Schwartz's (1994a) theory of human values. Each item described the values of an individual, and participants indicated on a six-point scale the degree to which they felt the statement described someone like them $(1=$ "Very much like me"; $6=$ "Not at all like me"). To ease interpretability, we recoded items such that higher scores would indicate higher endorsements of similarity.

Schwartz and colleagues (2012b) classify values into two higher-level categories: personal focus values and social focus values. Personal focus values tie closely to our conception of self-focused orientations, and touch on values to pursue one's self-interest (e.g., achieving power, status, enjoyable experiences), while also gaining new experiences and skills (which allow one to express greater personal mastery over the world around them). We therefore operationalized self-focused orientations using an average score of personal focus values assessed in the WVS (Schwartz et al., 2012b). In both waves, we used four items that measure values of self-direction, power, hedonism, and achievement. Sample items include "It is important to this person... to have a lot of money and expensive things" and "... to do things one's own way".

Social focus values tie closely to our conceptualization of other-focused orientations, and include values that concern others' wellbeing (e.g., doing good) and for interpersonal relationships and social order (e.g., conforming to social norms). We therefore operationalized other-focused orientations using an average score of values with a social focus (Schwartz et al., 2012b). We used three items in Wave 5, along with an additional fourth item included only in 
Wave 6 of the WVS, that measure values of benevolence, conformity, and universalism. Sample items include "It is important to this person... to always behave properly" and "... to do something for the good of society".

CFAs indicated all items significantly and positively $(p<.001)$ loaded onto their respective factors above .40 at both waves (see Figures S4 and S5 of the supplemental materials for full CFA results). Both scales had decent reliabilities ( $\alpha_{\mathrm{s}}$ ranged from .61 to .76).

\subsubsection{Prosocial behaviours and antisocial attitudes.}

In Wave 5, prosocial behaviours were assessed using two items asking individuals whether they were active members, inactive members, or non-members of (1) environmental, or (2) humanitarian or charitable organizations. We only considered active memberships in these organizations, as inactive memberships may not be as indicative of being engaged in prosocial behaviours promoted by these organizations (Parboteeah et al., 2004). Given relatively low membership rates, the two items were aggregated into a dichotomous measure assessing whether people were active members of either or both types of organizations (10.1\% of respondents) or not. The two items were correlated at .32. For Wave 6, we used two additional items assessing whether, in the prior two years, participants had (1) given money to an ecological organization, or (2) participated in a demonstration for an environmental cause. The four items in Wave 6 were aggregated into a dichotomous index to indicate whether individuals had engaged in any of the behaviours (21.4\% had done so). The four items in Wave 6 had $\alpha_{\mathrm{s}}=.50$.

Although Waves 5 and 6 did not collect data on antisocial behaviours directly, they contain several items assessing antisocial attitudes, which conceptually act as mediators between motivational orientations and behaviours, and can be used as a proxy measure indicating a proclivity towards antisocial behaviours. For Wave 5, we averaged five items asking participants 
the degree to which they thought certain antisocial behaviours were justifiable on a ten-point scale ( 1 = "Never justifiable"; 10 = "Always justifiable"). These behaviours included financial fraud (e.g., cheating on taxes) and violence (e.g., a man beating his wife), and the items had good reliability $\left(\alpha_{\mathrm{s}}=.80\right)$. The same items were used in Wave 6 , along with three additional items about: (1) stealing property; (2) parents beating children, and; (3) the use of violence against others. Items in Wave 6 also had good reliability $\left(\alpha_{\mathrm{s}}=.87\right)$. Raw scores on our measures of antisocial behaviours were skewed in both Waves, so we applied a log-transformation to normalize their distributions.

We conducted CFAs on the antisocial attitude items (Waves 5 and 6) and the prosocial behaviour items (Wave 6 only). All items significantly and positively $(p<.001)$ loaded onto their respective factor above .40 (except one prosocial behaviour item with a loading of .38; see Figures S6 and S7 of the supplemental materials for full CFA results).

\subsection{Analyses and Results}

We standardized all variables prior to analyses. We then conducted two separate multilevel models in each wave of the WVS, using the lme4 (Bates et al., 2015; 2018) and lmerTest packages (Kuznetsova et al., 2017).

First, we fitted a linear mixed effects model predicting antisocial attitudes from self- and other-focused orientations. Second, we fitted a mixed-effects logistic regression to predict engagement in prosocial behaviours, again using self- and other-focused orientations as predictors. In each model, data were nested within country, and random intercepts were estimated along with random effects for each predictor. Our results are presented in Table 4. Figure 2 displays the estimated within-country effects (i.e., magnitude of slopes for each country) in Wave 6. The distribution of within-country effects was similar in Wave 5 and is 
presented in Figure S8 of the supplemental files. Taken together, our analyses made use of data from 78 unique countries.

When modelling antisocial attitudes, self-focused orientations had a significant positive association with antisocial attitudes in both WVS waves $\left(\mathrm{H}_{1}\right)$. Estimated slopes were positive in $96 \%$ of countries in Wave 5, and in $85 \%$ of countries in Wave 6 . Conversely, other-focused orientations had significant negative associations with antisocial attitudes in both waves $\left(\mathrm{H}_{3}\right)$. Estimated slopes were negative in $98 \%$ of countries in Wave 5 and $100 \%$ of countries in Wave 6.

When modelling prosocial behaviours, self-focused orientations had a non-significant association with prosocial behaviours in Wave 5, but a significant positive association with prosocial behaviours in Wave $6\left(\mathrm{H}_{2}\right)$. Estimated slopes were positive in $67 \%$ of countries in Wave 5, and $78 \%$ of countries in Wave 6. Other-focused orientations had a significant positive association with prosocial behaviours in both Waves $\left(\mathrm{H}_{4}\right)$. Estimated slopes were positive in $100 \%$ of countries in Wave 5 , and $88 \%$ of countries in Wave 6.

Across models, effects associated with other-focused orientation were always significantly larger than corresponding effects associated with self-focused orientation, except when predicting prosocial behaviour in Wave $6\left(\mathrm{H}_{5}, \mathrm{H}_{6}\right)$. Lastly, the correlation between the two motivational measures was .29 in Wave 5 and .36 in Wave $6\left(\mathrm{H}_{7}\right)$, and the correlations between antisocial and prosocial behaviours were -.00 and $.08\left(\mathrm{H}_{8}\right)$. 
Table 4.

Results of Multi-Level Models Using Waves 5 and 6 of the World Values Survey

\begin{tabular}{|c|c|c|c|c|c|c|c|c|}
\hline \multicolumn{9}{|c|}{ (1) Linear Mixed-Effects Model Predicting Endorsement of Antisocial Attitudes } \\
\hline \multirow[t]{2}{*}{ Parameter } & \multicolumn{4}{|c|}{ Wave $5(N=70,956 ; k=51)$} & \multicolumn{4}{|c|}{ Wave $6(N=88,127, k=60)$} \\
\hline & Est. & SE/SD & $p$ & $99 \% C I$ & Est. & SE/SD & $p$ & $99 \% C I$ \\
\hline \multicolumn{9}{|l|}{ Fixed Effects } \\
\hline Intercept & .071 & .049 & .152 & {$[-.055, .196]$} & -.004 & .049 & .930 & {$[-.130, .121]$} \\
\hline Self-Focused Orientations $\left(\mathrm{H}_{1}\right)$ & .127 & .011 & $<.001$ & {$[.099, .156]$} & .083 & .138 & $<.001$ & {$[.047, .118]$} \\
\hline Other-Focused Orientations $\left(\mathrm{H}_{3}\right)$ & -.205 & .012 & $<.001$ & {$[-.234,-.175]$} & -.188 & .012 & $<.001$ & {$[-.218,-.158]$} \\
\hline \multicolumn{9}{|l|}{ Random Effects } \\
\hline Intercept & .120 & .346 & & & .142 & .377 & & \\
\hline Self-Focused Orientations & .005 & .074 & & & .011 & .103 & & \\
\hline Other-Focused Orientations & .006 & .077 & & & .007 & .086 & & \\
\hline
\end{tabular}

(2) Mixed-Effects Logistic Regression Predicting Engagement in Prosocial Behaviours

\begin{tabular}{|c|c|c|c|c|c|c|c|c|}
\hline \multirow{2}{*}{$\begin{array}{l}\text { Parameter } \\
\text { Fixed Effects }\end{array}$} & \multicolumn{4}{|c|}{ Wave $5(N=72,175, k=52)$} & \multicolumn{4}{|c|}{ Wave $6(N=88,720, k=60)$} \\
\hline & Est. & $S E / S D$ & $p$ & $99 \% C I$ & Est. & $S E / S D$ & $p$ & $99 \% C I$ \\
\hline \multicolumn{9}{|l|}{ Fixed Effects } \\
\hline Intercept & -2.594 & .151 & $<.001$ & {$[-2.983,-2.205]$} & -1.525 & .109 & $<.001$ & {$[-1.806,-1.244]$} \\
\hline Self-Focused Orientations $\left(\mathrm{H}_{2}\right)$ & .047 & .028 & .098 & {$[-.026, .120]$} & .148 & .030 & $<.001$ & {$[.071, .224]$} \\
\hline Other-Focused Orientations $\left(\mathrm{H}_{4}\right)$ & .326 & .030 & $<.001$ & {$[.250, .403]$} & .244 & .030 & $<.001$ & {$[.165, .322]$} \\
\hline \multicolumn{9}{|l|}{ Random Effects } \\
\hline Intercept & 1.160 & 1.077 & & & .706 & .840 & & \\
\hline Self-Focused Orientations & .020 & .142 & & & .044 & .209 & & \\
\hline Other-Focused Orientations & .021 & .144 & & & .046 & .214 & & \\
\hline
\end{tabular}

Note. $N=$ Number of participants; $k=$ Number of countries; Est. = Standardized parameter estimates; $S E=$ Standard Error (for fixed effects); $S D=$ Standard Deviation (for random effects); $p=p$ value; $C I$ s = Confidence Intervals, 99\% CIs were used instead of 95\% CIs given the large sample sizes of the WVS. Sample sizes varied across models depending on missing data, and whether a given country completed measures of a particular outcome variable. Results across the four models rely on data from 78 unique countries. Coefficients in bold font are significant at $p<.001$. 


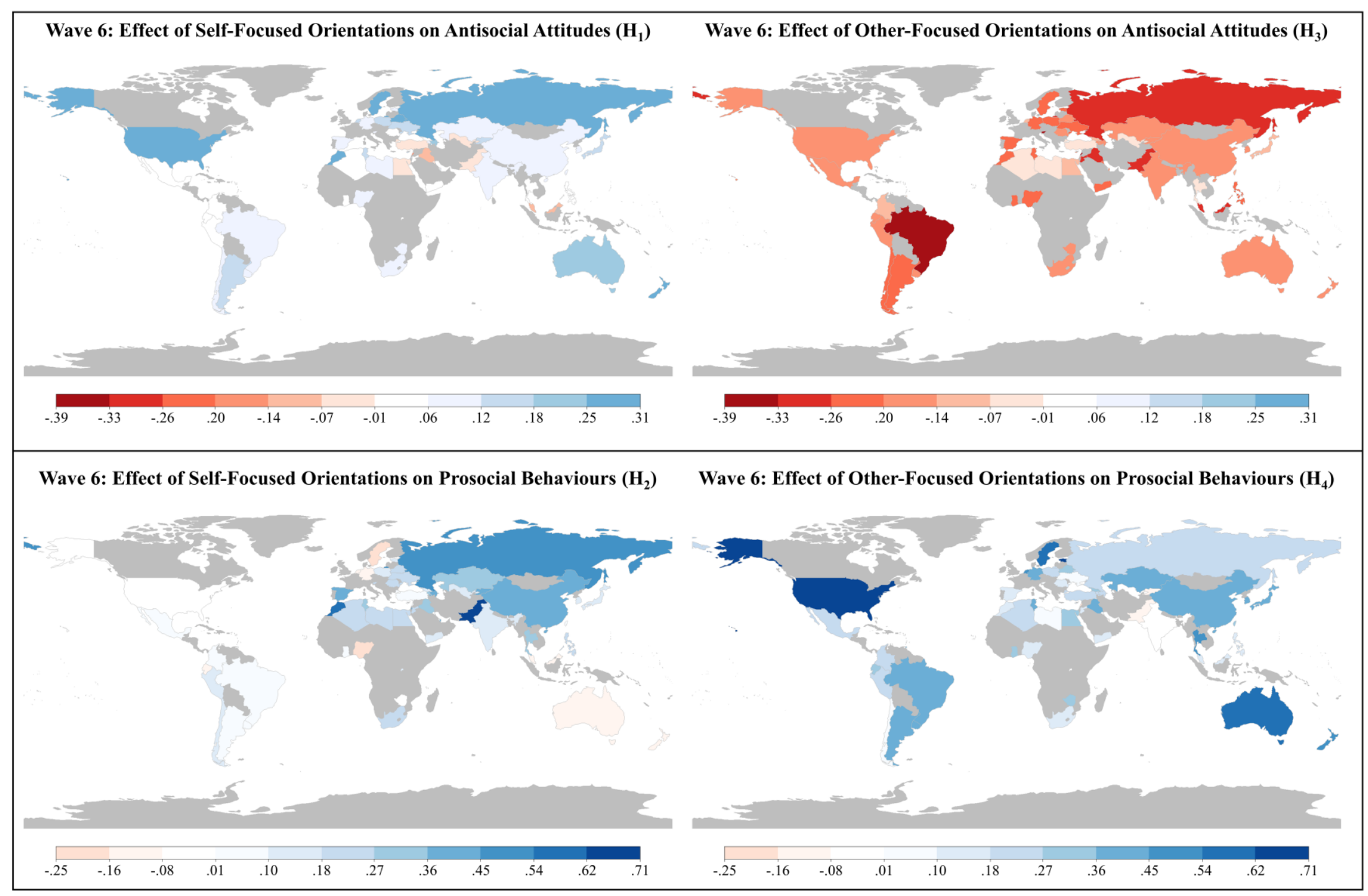

Figure 2. Graphical representation of Study 3 results (Wave 6 of the WVS). Darker blue colours indicate a stronger positive association within a given country, whereas darker red colours represent stronger negative associations. Countries in grey colour have no data available. The effects consist of the fixed effects, adjusted by the random effect estimate for each country. Maps were created using the rworldmap (South, 2011; 2016), classInt (Bivand, et al., 2018), and RColorBrewer (Neuwirth, 2011) packages. 


\subsection{Discussion}

Studies 2 and 3 build on Study 1 in several ways. They extend our analyses to different indicators of self-/other-focused orientations, and of prosocial/antisocial behaviours. In addition, they use substantially larger samples to provide increased reliability in our estimates, and extend our findings to an international context, allowing us to examine the degree to which our observed effects vary cross-nationally. Here, we summarize our findings.

How do self-focused orientations relate to our outcomes? We found significant positive associations between self-focused orientations and antisocial attitudes in both samples (averaging around estimates of .10), and these associations were highly consistent across countries. This provides good support for $\mathrm{H}_{1}$. We also observed a significant positive effect between selffocused orientations and prosocial behaviours in Wave 6, but not in Wave 5, and the average effect across waves was again near .10. Notably, there was substantial variation in the association between self-focused orientations and prosocial behaviours across countries, providing more mixed support for $\mathrm{H}_{2}$, suggesting that the association between self-focused orientations and prosocial behaviours may be variable across geographical contexts (e.g., see Figure 2).

What about the effects of other-focused orientations? We found that other-focused orientations had negative associations to antisocial attitudes, and positive associations to prosocial behaviours in both waves. These effects were moderate in magnitude (i.e., standardized regression effects between .2 and .3), and notably homogenous across countries (88-100\% of countries showed these associations). This provides clear support for $\mathrm{H}_{3}$ and $\mathrm{H}_{4}$.

When examining relative effect sizes (i.e., comparing CIs in Table 4), the effects of other-focused orientations were always larger than the effects of self-focused orientations. This 
difference was significant in three of four comparisons, providing good support for $\mathrm{H}_{5}$ and $\mathrm{H}_{6}$.

Finally, we found that self- and other-focused orientations had a moderate positive relationship to one-another, supporting $\mathrm{H}_{7}$. However, we did not find support for a negative association between antisocial attitudes and prosocial behaviours $\left(\mathrm{H}_{8}\right)$.

\section{Study 4}

Studies 2 and 3 benefitted from large samples drawn across many different countries. However, these studies relied on pre-existing datasets, thereby limiting our choice of measures. We only had access to an attitudinal measure of antisocial behaviours and a small sample of prosocial behaviours - the latter of which disproportionately focused on environment-related prosocial behaviours (which may be more strongly associated to values like universalism than other types of prosocial behaviours would be; Skimina et al., 2019). Although the self- and otherfocused orientation measures in the WVS are composite measures of various value constructs, they still represent only one additional operationalization of our constructs relative to Study 1 and had relatively low reliabilities. These factors leave open the possibility that we could obtain different results if we used alternative measures of our variables. Particularly, because we conceive self- and other-focused orientations as higher order classes of variables, we anticipate that differences can and should arise when using different lower-order constructs to operationalize them. For instance, both independence and power motivation are self-focused orientations; however, independence and power motivations are not themselves interchangeable, and are therefore free to diverge in their relations to other variables. Further, using more abstract and wide-ranging indices of self-focused and other focused orientations (e.g., broad differences in agency or in high-level values that are self-focused) should lead to more consistent patterns than using more specific indicators (e.g., independence and power motivations). Achieving an 
accurate understanding of self- and other-focused orientations as superordinate categories of constructs thus requires an adequate sampling of the constructs that make up these categories.

Consequently, in Study 4, we collected data with a more optimized set of measurements. Specifically, we examine effects associated with 19 distinct measures of self- and other-focused orientations, prosocial behaviours, and antisocial behaviours.

\subsection{Sample and Procedure}

Because our first three studies found several small effect sizes, we powered Study 4 to detect such effects. A power analysis using $G^{*}$ Power (Faul et al., 2009) suggested a sample of $N$ $=567$ would be enough to achieve a power of .95 for effects of $r=.15$. Using Amazon's Mechanical Turk (MTurk), we recruited 601 participants in February 2018. The study was approved by the institutional review board of the University of Minnesota, and all participants provided informed consent prior to participation.

To participate, individuals were required to be at least 18 years of age and residing within the United States. Participants completed a 30-minute survey online containing all our measures of interest. To promote data quality, the survey included 8 attention and honesty check items (see Table S9 of supplemental materials). Twenty-nine participants failed three or more items and were excluded, leaving 572 participants. The resulting sample was predominantly female (61\%), White/Caucasian $(79 \%)$, and had a mean age of 41.7 years $(S D=13.0)$. See Table $\mathrm{S} 10$ of supplemental materials for detailed Study 4 demographics.

\subsection{Constructs and Measures}

We used six measures of self- and other-focused orientations, respectively, four measures of prosocial behaviours, and three measures of antisocial behaviours. Each measure was scored using a two-parameter item-response theory (IRT) model, using the mirt package (Chalmers, 
2012), and a generalized partial credit model. Using IRT over classical test theory (e.g., taking the mean of items) allows us to reduce measurement error, while aiding to normalize our variables. Our data, survey materials, and $R$ script files can be found on our project page (osf.io/fwypt). Further, information on IRT analyses for each measure in Study 4 (item factor loadings, item discrimination, and item difficulty parameters) can be found in Tables S14 to S25 of the supplemental materials. Descriptive statistics and correlation matrices covering all our measures can also be found in Tables S26, S27 and S28.

\subsubsection{Self-focused and other-focused orientations.}

Table 5 summarizes the measures we used to assess motivational orientations, showing example items and reliability information for each scale. Table S11 of the supplemental materials provides a list of all the items that were used.

4.2.1.1. Assertiveness vs. compassion. The first scales completed by participants were the agreeableness and extroversion scales of the Big Five Aspects Scale (BFAS; DeYoung et al., 2007). In the BFAS, extroversion is broken down into the two aspects of assertiveness and enthusiasm, whereas agreeableness is broken down into compassion and politeness. We focused our analyses on the aspects of assertiveness and compassion. Respectively, these correspond closely to the agency and communion dimensions of the interpersonal circumplex and can interchangeably be used as measures of these dimensions (DeYoung et al., 2007; 2013). As previously noted, agency and communion differ in the extent to which they are concerned with seeking benefits for the self and for others (Abele \& Wojciszke, 2007). 
Table 5.

Summary of Study 4 Measures to Assess Self-Focused Orientations and Other-Focused Orientations.

\begin{tabular}{|c|c|c|c|c|c|}
\hline Measure & Scales & $\alpha_{\mathrm{s}}$ & $\begin{array}{l}\text { Example Items, in reference to self. } \\
\text { (and reverse-coded items if present) }\end{array}$ & $\begin{array}{l}\text { Response Range and } \\
\text { Anchors }\end{array}$ & $\begin{array}{l}r \text { between } \\
\text { scales }\end{array}$ \\
\hline BFAS & $\begin{array}{l}\text { Assertiveness } \\
\text { Compassion }\end{array}$ & $\begin{array}{l}.88 \\
.91\end{array}$ & $\begin{array}{l}\text { Have a strong personality } \\
\text { Wait for others to lead the way } \\
\text { Take an interest in other people's lives } \\
\text { Am indifferent to the feelings of others }\end{array}$ & $\begin{array}{l}1=\text { strongly disagree } \\
5=\text { strongly agree }\end{array}$ & .18 \\
\hline PVQ5X & $\begin{array}{l}\text { Personal focus } \\
\text { values } \\
\text { Social Focus } \\
\text { Values }\end{array}$ & $\begin{array}{l}.90 \\
.92\end{array}$ & $\begin{array}{l}\text { It is important to me to make my own } \\
\text { decisions about my life } \\
\text { I strongly value the traditional practices } \\
\text { of my culture }\end{array}$ & $\begin{array}{l}1=\text { strongly agree; } \\
7=\text { strongly agree }\end{array}$ & .63 \\
\hline SCS & $\begin{array}{l}\text { Independent } \\
\text { Self-Construal } \\
\text { Interdependent } \\
\text { Self-Construal }\end{array}$ & $\begin{array}{l}.81 \\
.85\end{array}$ & $\begin{array}{l}\text { I enjoy being unique and different from } \\
\text { others in many respects } \\
\text { My happiness depends on the happiness } \\
\text { of those around me }\end{array}$ & $\begin{array}{l}1=\text { strongly agree; } \\
7=\text { strongly agree }\end{array}$ & .28 \\
\hline SOI & $\begin{array}{l}\text { Self-Interest } \\
\text { Other-Interest }\end{array}$ & $\begin{array}{l}.88 \\
.90\end{array}$ & $\begin{array}{l}\text { I keep an eye out for my interests } \\
\text { I keep an eye out for other's interests }\end{array}$ & $\begin{array}{l}1=\text { strongly agree; } \\
7=\text { strongly agree }\end{array}$ & .61 \\
\hline UMS & $\begin{array}{l}\text { Power } \\
\text { Motivation } \\
\text { Achievement } \\
\text { Motivation } \\
\text { Affiliation } \\
\text { Motivation } \\
\text { Intimacy } \\
\text { Motivation } \\
\end{array}$ & $\begin{array}{l}.92 \\
.90 \\
.92\end{array}$ & $\begin{array}{l}\text { To be able to exert influence } \\
\text { My goal is to do at least a little bit more } \\
\text { than anyone else has done before } \\
\text { I like to make as many friends as I can } \\
\text { To have a close, intimate relationship } \\
\text { with someone }\end{array}$ & $\begin{array}{l}1 \text { = strongly disagree/not at } \\
\text { all important; } \\
7 \text { = strongly } \\
\text { agree/extremely important }\end{array}$ & .25 to $.56^{\mathrm{b}}$ \\
\hline
\end{tabular}

Note. $\alpha_{\mathrm{s}}=$ standardized reliability alpha; $r=$ Pearson bivariate correlation; BFAS = Big Five Aspects Scale (DeYoung et al., 2007); PVQ5X = Portrait Values Questionnaire 5X Value Survey (Schwartz et al., 2012a, 2012b); SCS = Self-Construal Scale (Singelis, 1994); SOI = Self- and Other-Interest Inventory (Gerbasi \& Prentice, 2013); UMN = Unified Motives Scales (Schönbrodt \& Gerstenberg, 2012).

${ }^{a}$ Reverse-coded item.

${ }^{b}$ Range corresponds to the correlations between any given self-focused measure (power \& achievement) and any given other-focused measure (affiliation and intimacy). 
4.2.1.2. Personal focus values vs. social focus values. Value orientations were assessed using an adapted version of the Portrait Values Questionnaire 5X Value Survey (PVQ5X; Schwartz et al., 2012a, 2012b) asking participants to rate the importance of 19 values using 48 items. Items can be used to represent two higher order factors of personal and social focus values (Schwartz et al., 2012b). Personal focus values include self-direction, stimulation, hedonism, achievement, power, face, and personal security. Social focus values include universalism, benevolence, humility, conformity, tradition, and societal security.

4.2.1.3. Independent self-construal vs. interdependent self-construal. Self-construal was assessed using Singelis' (1994) Self-Construal Scale (SCS). The SCS consists of two 12-item scales. The first scale assesses independent self-construal, defined as the degree to which a person conceives their sense of self in terms of its autonomy and independence (Markus \& Kitayama, 1991; Singelis, 1994). Independent self-construal is a self-focused orientation and reflects motivations to express/strengthen one's autonomy and independence. The second scale measures interdependent self-construal, the degree to which a person conceives their sense of self as fundamentally embedded in and dependent on those around them (Markus \& Kitayama, 1991; Singelis, 1994). Interdependent self-construal is an other-focused orientation, and reflects motivations to maintain/promote social connections, largely by adhering to social norms.

4.2.1.4. Self-interest vs. other-interest. The Self- and Other-Interest Inventory (Gerbasi \& Prentice, 2013) consists of two nine-item scales, which directly assess the extent to which individuals are interested and motivated to act in their own self-interest (e.g., by achieving social success, happiness) or in other people's interest (i.e., other-interest; e.g., by helping others achieve social success and happiness).

4.2.1.5. Power and achievement motives vs. affiliation and intimacy motives. The final 
measure was an adaptation of the Unified Motives Scales by Schönbrodt and Gerstenberg (2012). This measure consists of four ten-item scales, containing a mixture of statements describing the self or various goals a person may have. The first two scales assess self-focused orientations: power motivation (the desire to impact/control others and achieve personal success) and achievement motivation (the desire to learn and master tasks to demonstrate personal excellence). Two other scales assess other-focused orientations: affiliation motivation (the desire to build/maintain friendly relationships with others in general) and intimacy motivation (the desire to form profound mutual relationships with specific close others).

\subsubsection{Measures of prosocial and antisocial behaviours.}

Table 6 summarizes the measures we used to assess prosocial and antisocial behaviours and provides sample items and reliability information. Tables S12 and S13 of the supplemental materials list all items used.

4.2.2.1. Prosocial behaviours. Participants first completed 12-items from the Self-Report Altruism scale (Rushton et al., 1981). Each item described a prosocial behaviour, and participants indicated the frequency with which they enacted the behaviour in the past. Second, participants completed a helping attitudes scale (Fetzer Institute, n.d.; Nickell, 1998), consisting of 20 items assessing attitudes toward helping, helping intentions, and helping behaviour. Given that this scale is not entirely composed of behavioural measures, we interpret it as a proxy measure of one's likelihood to engage in prosocial behaviours. Third, participants completed 14 items assessing organizational citizenship behaviours (OCB; adapted from Hui et al., 1999, and Podsakoff et al., 1990). OCBs are a form of prosocial behaviour directed towards improving the functioning of a workplace. The items we used each describe behaviours that bring direct benefits to organizations and co-workers. Individuals were instructed to report their behaviour 
Table 6.

Summary of Study 4 Measures to Assess Prosocial and Antisocial Behaviours.

\begin{tabular}{|c|c|c|c|c|}
\hline & Measure & $\alpha_{\mathrm{s}}$ & Example Items & $\begin{array}{l}\text { Response Range and } \\
\text { Anchors }\end{array}$ \\
\hline \multirow{4}{*}{ 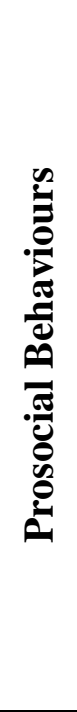 } & $\begin{array}{l}\text { Self-Report Altruism } \\
\text { Scale (Rushton et al., } \\
\text { 1981) }\end{array}$ & .88 & $\begin{array}{l}\text { I have given money to a charity; } \\
\text { I have delayed an elevator and held the door open } \\
\text { for a stranger }\end{array}$ & $\begin{array}{l}1=\text { never; } \\
5=\text { very frequently }\end{array}$ \\
\hline & $\begin{array}{l}\text { Helping Attitudes } \\
\text { Scale (Nickell, 1998) }\end{array}$ & .91 & $\begin{array}{l}\text { It feels wonderful to assist others in need; } \\
\text { I donate time or money to charities every month }\end{array}$ & $\begin{array}{l}1=\text { disagree strongly; } \\
5=\text { agree strongly }\end{array}$ \\
\hline & $\begin{array}{l}\text { OCB Scale (Hui et al., } \\
\text { 1999; Podsakoff et al., } \\
\text { 1990) }\end{array}$ & .91 & $\begin{array}{l}\text { I spend time helping others catch up when they } \\
\text { have been absent } \\
\text { I volunteer time to help others who have work } \\
\text { related problems }\end{array}$ & $\begin{array}{l}1=\text { disagree strongly; } \\
5=\text { agree strongly }\end{array}$ \\
\hline & $\begin{array}{l}\text { Volunteerism and } \\
\text { donations Measure }\end{array}$ & .67 & $\begin{array}{l}\text { During the last } 12 \text { months, have you donated } \\
\text { blood, plasma, or platelets? } \\
\text { Are you an active member of either of the } \\
\text { following types of organizations? (Humanitarian } \\
\text { or charitable organization) }\end{array}$ & "Yes" or "No" \\
\hline \multirow{3}{*}{ 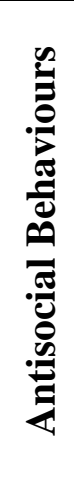 } & $\begin{array}{l}\text { Aggression } \\
\text { Questionnaire (Buss \& } \\
\text { Perry, 1992) }\end{array}$ & .93 & $\begin{array}{l}\text { If somebody hits me, I hit back } \\
\text { I have threatened people I know }\end{array}$ & $\begin{array}{l}1=\text { disagree strongly; } \\
5=\text { agree strongly }\end{array}$ \\
\hline & $\begin{array}{l}\text { CWB-C (Spector et al., } \\
\text { 2006) }\end{array}$ & .98 & $\begin{array}{l}\text { Purposely wasted your employer's } \\
\text { materials/supplies } \\
\text { Stole something belonging to someone at work }\end{array}$ & $1=$ never $; 5=$ every day \\
\hline & $\begin{array}{l}\text { Illicit Antisocial } \\
\text { Behaviours Measure }\end{array}$ & .92 & $\begin{array}{l}\text { In the past } 12 \text { months, how often did you } \\
\ldots \text { steal something worth less than } \$ 50 \text { ? } \\
\ldots \text { hurt someone badly enough in a physical fight } \\
\text { that he or she needed care from a doctor or nurse? }\end{array}$ & Varied by item \\
\hline
\end{tabular}

Note. $\alpha_{\mathrm{s}}=$ standardized reliability alpha; $\mathrm{OCB}=$ organizational citizenship behaviour; $\mathrm{CWB}-\mathrm{C}=$ counterproductive work behaviour checklist. 
from either their current or last place of employment. Fourth, we included all seven prosocial behaviour items used across Studies 1,2, and 3 to measure volunteerism and donations.

4.2.2.1. Antisocial behaviours. First, participants completed 21 items to indicate the degree to which they displayed explicit behavioural aggression towards others (selected from Buss \& Perry, 1992). Second, participants responded to 39 items measuring counterproductive work behaviours (CWBs; using items from the Counterproductive Work Behavior Checklist, Spector et al., 2006). CWBs are defined as workplace behaviours that harm organizations or their members (Dalal, 2005), and we only used items that referred explicitly to enacting antisocial behaviours in the workplace. As with OCB, participants either reported on their current or last employment. Third, we used ten items identical to those in Study 1 to measure illicit antisocial behaviours.

\subsubsection{Creating aggregate measures.}

Finally, we created aggregate measures composed of all the items for self-focused orientations (73 items; $\alpha_{\mathrm{s}}=.96$ ), other-focused orientations (77 items; $\left.\alpha_{\mathrm{s}}=.96\right)$, prosocial behaviours (52 items; $\alpha_{\mathrm{s}}=.94$ ), and antisocial behaviours (70 items; $\alpha_{\mathrm{s}}=.98$ ). To obtain scores, we applied our IRT scoring procedure to the items within each class of variables. Although these aggregate measures do not allow us to examine heterogeneity between scales, they offer two advantages. First, they are closer representations of our hypotheses regarding self- and otherfocused variables as higher-order individual difference variables. Second, aggregating across instantiations of the predictor and outcome variables may lead to a more powerful test of their association (Epstein, 1979; 1980).

\subsection{Analyses and Results}

\subsubsection{Examining effects on each individual measure.}


Table 7 presents the results of five SEM models using FIML, conducted with lavaan (Rosseel, 2012). Each model was computed according to the structural relations in Figure 1. Models 1 to 5 break the analyses down according to each measure of self- and other-focused orientations, and simultaneously predict each index of antisocial and prosocial behaviours. For example, Model 1 examines how assertiveness and compassion simultaneously predict the three indices of antisocial behaviours and the four indices of prosocial behaviours, while accounting for correlations between predictor variables and between outcome variables.

Table 7 reports 18 tests of the link between self-focused orientations and antisocial behaviours $\left(\mathrm{H}_{1}\right)$; of these, 9 were significant and positive, and the average standardized coefficient was .08. There were 24 tests of the link between self-focused orientations and prosocial behaviours $\left(\mathrm{H}_{2}\right)$; of these, 10 were significant and positive, and the average standardized coefficient was again .08. There were 18 tests of the link between other-focused orientations and antisocial behaviours $\left(\mathrm{H}_{3}\right)$; of these, 13 were significant and negative, and the average standardized coefficient was -.19. Finally, there were 24 tests of the link between otherfocused orientations and prosocial behaviours $\left(\mathrm{H}_{4}\right)$; of these, 22 were significant and positive, and the average standardized coefficient was .31 .

We can compare the relative effect sizes associated with self- and other-focused orientations in each model in Table 7. For instance, in Model 1, we can compare the effect sizes of assertiveness vs. compassion in predicting (1) aggression, (2) counter-productive work behaviours, and (3) illicit antisocial behaviours - in all three cases, the effect associated with compassion was significantly more negative than that associated with assertiveness. Models 2, 3, and 4 each provide three similar comparisons (one per indicator of antisocial behaviours), and Model 5 provides 12 comparisons (i.e., for each indicator, we can compare the effects of: power 
Table 7.

Standardized Parameter Estimates and Confidence Intervals from SEM Models Predicting Antisocial/Prosocial Behaviours from Motivational Orientations.

\begin{tabular}{|c|c|c|c|c|c|c|c|c|}
\hline & \multirow{2}{*}{ Predictors } & \multicolumn{3}{|c|}{ Predicting Antisocial Behaviours $\left(\mathrm{H}_{1} \& \mathrm{H}_{3}\right)$} & \multicolumn{4}{|c|}{ Predicting Prosocial Behaviours $\left(\mathrm{H}_{2} \& \mathrm{H}_{4}\right)$} \\
\hline & & $\mathbf{A}$ & CWB & IAB & SRA & HA & OCB & VD \\
\hline \multirow{4}{*}{$\frac{\bar{\theta}}{\frac{\bar{\theta}}{8}}$} & 1. Assertiveness & $.073^{\mathrm{t}}$ & -.031 & $.129 * *$ & $.231 * *$ & .026 & $.158 * *$ & $.170 * *$ \\
\hline & & {$[.000, .147]$} & {$[-.111, .048]$} & {$[.049, .210]$} & {$[.156, .307]$} & {$[-.035, .087]$} & {$[.088, .229]$} & {$[.402, .529]$} \\
\hline & 2. Compassion & $-.478 * *$ & $-.300 * *$ & $-.212 * *$ & $.255 * *$ & $.676 * *$ & $.465 * *$ & $.127 * *$ \\
\hline & & {$[-.543,-.413]$} & {$[-.377,-.224]$} & {$[-.291,-.132]$} & {$[.180, .330]$} & {$[.630, .721]$} & {$[.402, .529]$} & {$[.046, .207]$} \\
\hline \multirow{4}{*}{$\frac{N}{\frac{D}{O}}$} & 1. Personal Focus & $.284 * *$ & .074 & $.160 * *$ & $.089^{t}$ & $-.085^{*}$ & $.114 * *$ & .051 \\
\hline & Values & {$[.191, .377]$} & {$[-.028, .176]$} & {$[.056, .263]$} & {$[-.011, .188]$} & {$[-.1 \overline{63,-.008]}$} & {$[.030, .198]$} & {$[-.054, .156]$} \\
\hline & 2. Social Focus & $-.570 * *$ & $-.339 * *$ & $-.203 * *$ & $.271 * *$ & $.732 * *$ & $.528 * *$ & .079 \\
\hline & Values & {$[-.656,-.485]$} & {$[-.438,-.241]$} & {$[-.306,-.100]$} & {$[.174, .369]$} & {$[.668, .796]$} & {$[.451, .605]$} & {$[-.026, .184]$} \\
\hline \multirow{4}{*}{$\frac{m}{\frac{m}{0}}$} & 1. Independent & $-.188 * *$ & $-.235^{* *}$ & .014 & $.227 * *$ & $.272 * *$ & $.341 * *$ & .057 \\
\hline & Self-Construal & {$[-. \overline{270,-.107]}$} & {$[-. \overline{316,-}-154]$} & {$[-.071, .100]$} & {$[.150, .304]$} & {$[.199, .346]$} & {$[.275, .408]$} & {$[-.028, .141]$} \\
\hline & 2. Interdependent & $-.101 *$ & -.062 & .028 & $.247 * *$ & $.314 * *$ & $.383 * *$ & $.095 *$ \\
\hline & Self-Construal & {$[-.183,-.018]$} & {$[-.145, .021]$} & {$[-.058, .113]$} & {$[.170, .324]$} & {$[.242, .386]$} & {$[.318, .449]$} & {$[.011, .180]$} \\
\hline \multirow{4}{*}{$\begin{array}{l}\frac{\nabla}{0} \\
\frac{0}{0} \\
\sum\end{array}$} & 1. Self-Interest & $.366 * *$ & $.166 * *$ & $.170 * *$ & -.031 & $-.237 * *$ & $-.092 *$ & .004 \\
\hline & & {$[.272, .460]$} & {$[.065, .267]$} & {$[.068, .271]$} & {$[-.124, .062]$} & {$[-.327,-.147]$} & {$[-.1 \overline{77,-.007]}$} & {$[-.097, .104]$} \\
\hline & 2. Other-Interest & $-.340 * *$ & $-.227 * *$ & -.074 & $.451 * *$ & $.574 * *$ & $.614 * *$ & $.223 * *$ \\
\hline & & {$[-.434,-.245]$} & {$[-.327,-.126]$} & {$[-.176, .028]$} & {$[.364, .538]$} & {$[.493, .656]$} & {$[.540, .689]$} & {$[.125, .322]$} \\
\hline \multirow{8}{*}{$\frac{n}{\frac{0}{0}}$} & 1. Power & $.488 * *$ & $.245 * *$ & $.263 * *$ & .012 & $-.381 * *$ & $-.207 * *$ & .026 \\
\hline & Motivation & {$[.390, .585]$} & {$[.136, .354]$} & {$[.154, .371]$} & {$[-.091, .114]$} & {$[-. \overline{469,-.294]}$} & {$[-. \overline{295,-.119]}$} & {$[-.083, .135]$} \\
\hline & 2. Achievement & $-.205^{* *}$ & $-.168 * *$ & $-.104^{t}$ & $.207 * *$ & $.378 * *$ & $.446 * *$ & $.122 *$ \\
\hline & Motivation & {$[-. \overline{302,-.107]}$} & {$[-. \overline{273,-}-.063]$} & {$[-.209, .001]$} & {$[.110, .304]$} & {$[.296, .461]$} & {$[.365, .527]$} & {$[.018, .226]$} \\
\hline & 3. Affiliation & $-.162 * *$ & -.007 & .025 & $.165 * *$ & -.002 & $.089^{t}$ & $.202 * *$ \\
\hline & Motivation & {$[-.268,-.056]$} & {$[-.120, .107]$} & {$[-.089, .139]$} & {$[.060, .270]$} & {$[-.094, .089]$} & {$[-.002, .181]$} & {$[.091, .313]$} \\
\hline & 4. Intimacy & $-.159 * *$ & $-.136 * *$ & -.067 & $.143 * *$ & $.461 * *$ & $.325 * *$ & -.025 \\
\hline & Motivation & {$[-.254,-.064]$} & {$[-.238,-.034]$} & {$[-.169, .035]$} & {$[.049, .238]$} & {$[.383, .539]$} & {$[.245, .406]$} & {$[-.126, .076]$} \\
\hline
\end{tabular}

Note. ${ }^{\mathrm{t}} p<.10 ;{ }^{*} p<.05 ; * * p<.01 . \mathrm{A}=$ Aggression; CWB = Counterproductive Work Behaviours; IAB = Illicit Antisocial

Behaviours; SRA = Self-Report Altruism; HA = Helping Attitudes; OCB = Organization Citizenship Behaviours; VD = Volunteerism and Donations. Significant estimates in hypothesized direction are bolded; significant estimates counter to hypothesized direction are underlined. Grey font indicates non-significant effects. Models are just-identified, so fit indices are not reported. Covariance estimates between predictors in each model $\left(\mathrm{H}_{7}\right)$ average around .426 , whereas average covariance between indicators of prosocial/antisocial behaviours $\left(\mathrm{H}_{8}\right)$ is -.017. Each predictor and outcome measure was scored using a two-parameter item-response theory (IRT) model. 
vs. affiliation, power vs. intimacy, achievement vs. power, and achievement vs. intimacy). Doing this across all five models, 24 pathway pairs can be used to evaluate the relative strength of selfversus other-focused orientations in accounting for antisocial behaviours $\left(\mathrm{H}_{5}\right)$. When predicting antisocial behaviours, other-focused orientations had a significantly more negative association than self-focused orientations 15 times, and a significantly less negative associations only once (i.e., in Model 3, independent self-construal has a significantly more negative effect than interdependent self-construal in predicting counterproductive work behaviours). When predicting prosocial behaviours, we can compare 32 pathway pairs $\left(\mathrm{H}_{6}\right)$. Other-focused orientations were significantly more positively associated with prosocial behaviours in 12 comparisons, and significantly less positively associated in only 2 comparisons.

To evaluate $\mathrm{H}_{7}$, we compared 36 correlations between self- and other-focused orientation measures. The average correlation was .34 (range of -.16 to .63; with 22 correlations being between .2 and .5 ). To evaluate $\mathrm{H}_{8}$, we compared 12 correlations between prosocial and antisocial behaviour indices. The average correlation was -.08 (range of -.46 to .15; with 7 correlations between 0 and -.5).

\subsubsection{Examining effects using the four aggregate measures.}

A sixth SEM model (again using FIML) examined the association between our four aggregate measures, and was specified exactly according to Figure 1. The results are presented in Figure 3. Self-focused orientations had a significant positive association with antisocial behaviours $\left(\mathrm{H}_{1}\right)$ but not with prosocial behaviours $\left(\mathrm{H}_{2}\right)$. In contrast, other-focused orientations had a significant negative association with antisocial behaviours $\left(\mathrm{H}_{3}\right)$ and a significant positive association with prosocial behaviours $\left(\mathrm{H}_{4}\right)$. The effects associated with other-focused orientations were significantly larger in magnitude than the effects associated with self-focused 
orientations $\left(\mathrm{H}_{5}\right.$ and $\left.\mathrm{H}_{6}\right)$. Finally, examining bivariate correlations reveals that self- and otherfocused orientations were significantly positively associated $\left(r=.54 ; \mathrm{H}_{7}\right)$, and antisocial/prosocial behaviours were significantly negatively associated $\left(r=-.39 ; \mathrm{H}_{8}\right)$.

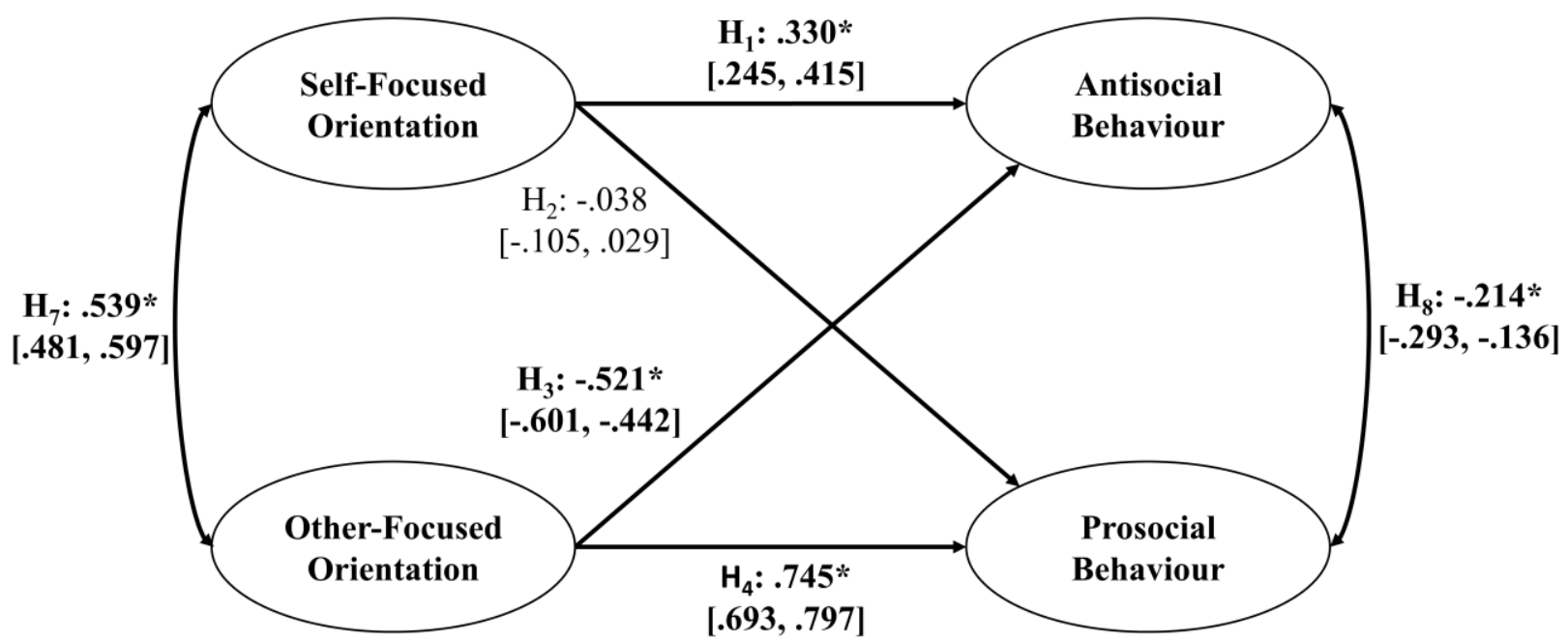

Figure 3. Structural equation model aggregating indices of each variable type. Confidence intervals for structural portion of the model are presented in the square brackets. For the structural paths, an asterisk (*) indicates a p value below .001. Model was just-identified, so model fit indices are not reported. Each predictor and outcome measure was scored by applying a two-parameter item-response theory (IRT) model to all items of a given construct type.

\subsubsection{Alternate analyses to evaluate robustness of findings.}

When conducting Study 4, we generally opted to retain items from existing measures (e.g., we used the full interdependence self-construal scale as developed by Singelis, 1994) to allow for our findings to be comparable to other studies using the same measures. However, a limitation of this approach is that several items used to assess people's motivational orientations were indicators of antisocial or prosocial behaviours/intentions (e.g., "I would offer my seat in a bus to an authority figure" in the interdependent self-construal measure), and certain items used to assess prosocial/antisocial outcomes may be more reflective of motivational orientations (e.g., "It feels wonderful to assist others in need" in the helping attitudes measure).

To address these issues, we ran additional analyses removing all such items (45 items in 
total). Figure 4 gives a sample of the results by presenting the SEM model that examined the link between the aggregate measures constructed from the revised scales. Other results are presented in full in our supplemental materials (Section 4, including Tables S29-S32 and Figure S9).

Generally, our inferences remain unchanged across these analyses. Differences in our findings included: (1) the association between various self-focused orientations and prosocial behaviours became more positive, in line with $\mathrm{H}_{2}$; (2) the association between various other-focused orientations and prosocial behaviours declined in magnitude but was still typically significant and positive, in line with $\mathrm{H}_{4}$, and; (3) the association between prosocial and antisocial behaviours was reduced, compared to $\mathrm{H}_{8}$.

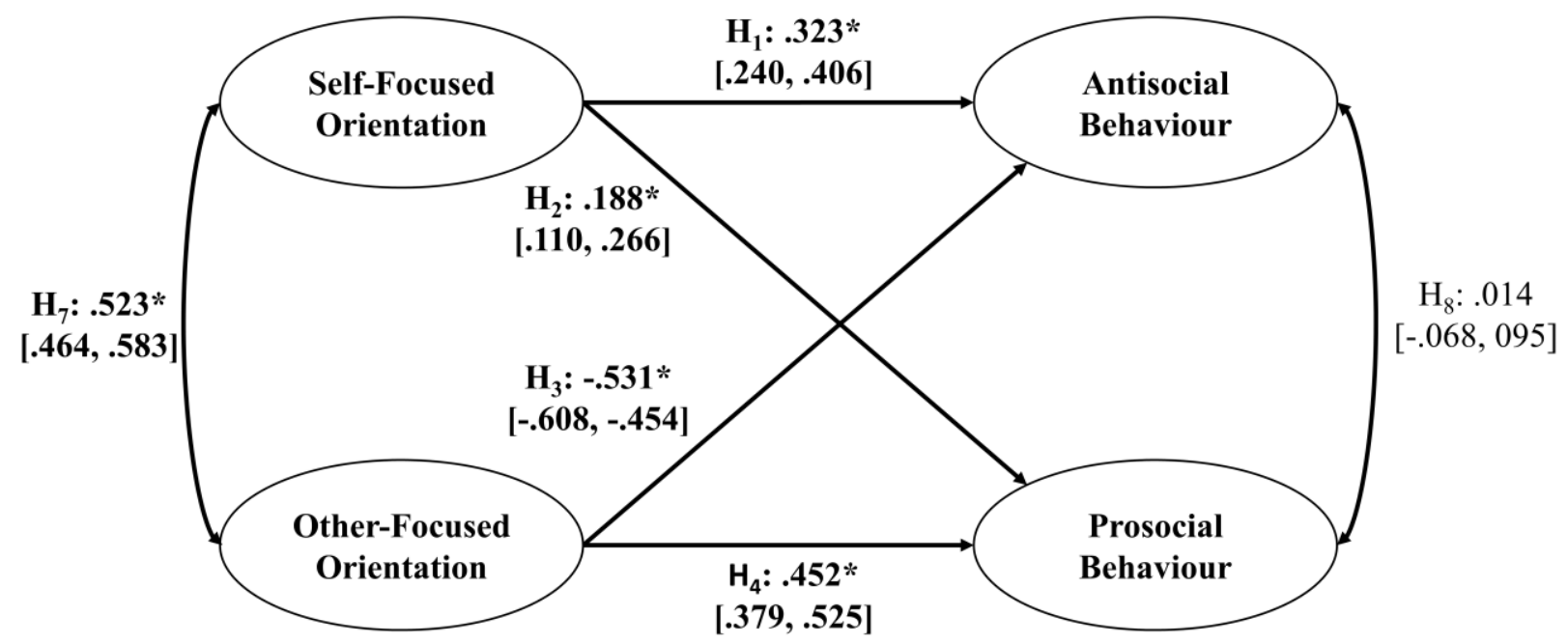

Figure 4. Structural equation model aggregating indices of each variable type, using an alternate selection of items to reflect each construct (i.e., removing 45 items to ensure predictors and outcomes were maximally differentiated). Confidence intervals for structural portion of the model are presented in the square brackets. For the structural paths, an asterisk (*) indicates a $\mathrm{p}$ value below .001. Model was just-identified, so model fit indices are not reported. Each predictor and outcome measure was scored by applying a two-parameter item-response theory (IRT) model to all items of a given construct type.

\subsection{Discussion}

The goals of Study 4 were to examine: (1) the overall pattern of associations that emerge across different indicators of each of our variables, and (2) the degree to which these associations 
vary depending on the specific measures/operationalizations we use. In this study, we also aimed to use more reliable measures of each of our constructs by relying heavily on well-established measures. The resulting high reliability of the scales (average $\alpha_{\mathrm{s}}=.89$ ) helps us gain confidence in our findings. How did our hypotheses fare in Study 4 ?

Our findings provide support for $\mathrm{H}_{1}$ such that self-focused orientations tended to be positively associated with antisocial behaviours, and our aggregate measures also showed a moderate positive association with antisocial behaviours. However, when examining specific types of self-focused orientations, heterogeneity was observed such that certain indicators showed no effects (e.g., assertiveness was not associated with aggression or CWB), and some even showed negative associations (e.g., independent self-construal was negatively associated with aggression and CWB).

Our results provide mixed support for $\mathrm{H}_{2}$ : Self-focused orientations were indeed more frequently positively (rather than negatively) associated with prosocial behaviours, but there was a fair amount of heterogeneity in this association. Also, the aggregate measures showed a nonsignificant association.

Exploring the heterogeneity in the above findings, we note that more abstract constructs such as agency and personal focus values, along with our aggregate index of self-focused orientation, each showed patterns largely in line with our hypotheses. As expected, most deviations from our hypotheses were observed when looking at specific lower-order constructs (e.g., self-construal). Examining these deviations could provide insights into subclasses of selffocused orientations. For example, independent self-construal and achievement motivation both had negative associations with antisocial behaviours and positive associations with prosocial behaviours. This pattern may suggest that self-focused orientations directed towards goals such 
as achieving competence, autonomy, and growth, may be more adaptive than other forms of selffocused orientations. In contrast, indicators of self-interest and power motivation had clear positive associations with antisocial behaviours and negative associations with prosocial behaviours, suggesting that orientations tied to competitive and power-driven themes may be associated with greater engagement in detrimental social behaviours.

In comparison to the effects associated with self-focused orientations, the effects associated with other-focused orientations were considerably less heterogeneous. Other-focused orientations had mostly negative associations with antisocial behaviour indices, and almost entirely positive associations with prosocial behaviours. This pattern of results provides clear support for $\mathrm{H}_{3}$ and $\mathrm{H}_{4}$.

We also found support for $\mathrm{H}_{5}$ and $\mathrm{H}_{6}$. The associations between other-focused orientations and prosocial/antisocial behaviours were indeed typically significantly larger (in the expected direction) than the associations between indices of self-focused orientations and prosocial/antisocial behaviours. On average, without aggregating, the effect sizes associated with other-focused orientations were moderate in magnitude (standardized coefficients around .2 to .3), whereas the average effect sizes associated with self-focused orientations were small (around .1). Hypotheses $\mathrm{H}_{5}$ and $\mathrm{H}_{6}$ were also supported when using aggregate measures.

Finally, in line with $\mathrm{H}_{7}$, we found self- and other-focused orientations to be generally moderately positively associated (average $r=.34$ ). The association between antisocial and prosocial behaviours was, on average, small and negative, but varied highly across operationalizations (ranging between $r=-.46$ to .39 ). Given this heterogeneity, Study 4 provides mixed support for $\mathrm{H}_{8}$. 


\section{General Discussion}

We examined the extent to which self- and other-focused orientations predicted prosocial and antisocial outcomes similarly or differently across four samples that together represent a wide range of demographics (e.g., age, nationality). In addition, we used multiple operationalizations of our key constructs to test the independent and combined effects of various measures. We synthesize the results of Studies 1 through 4 and discuss the implications of our findings. Table 8 provides an overview of the findings and our overall conclusions.

\subsection{How do Self-Focused Orientations Relate to Prosocial and Antisocial Behaviours (H1- $\left.\mathbf{H}_{2}\right)$ ?}

Across our studies, we find consistent support for a general positive association between self-focused orientations and antisocial behaviours $\left(\mathrm{H}_{1}\right)$. On average, this occurred both crossnationally and across construct operationalizations, but there was a decent amount of heterogeneity in effect sizes across operationalizations of self-focused orientations. We also found that self-focused orientations were, in general, positively associated with prosocial behaviours $\left(\mathrm{H}_{2}\right)$, but this association was more variable cross-nationally (Studies 2 and 3; see Figures 2 and S8) and across different types of indicators (Study 4) than the association between self-focused orientations and antisocial behaviours.

Overall, the implication is that self-focused orientations may generally positively predict both antisocial and prosocial behaviours, or at least positively predict antisocial (but not consistently prosocial) behaviours. Either pattern makes them risky targets for interventions, especially if one seeks to increase prosocial behaviours by increasing self-focused orientations. In such a case, our results suggest mixed evidence this would successfully increase prosocial behaviours and suggest a threat of unintentionally increasing antisocial behaviours. This is 
Table 8.

Synthesis of Findings from the Four Studies.

\begin{tabular}{|c|c|c|c|c|c|c|c|c|c|}
\hline & \multicolumn{8}{|c|}{ Hypotheses } \\
\hline & & $\mathbf{H}_{1}$ & $\mathbf{H}_{2}$ & $\mathbf{H}_{3}$ & $\mathbf{H}_{4}$ & $\mathbf{H}_{5}$ & $\mathbf{H}_{6}$ & $\mathbf{H}_{7}$ & $\mathbf{H}_{8}$ \\
\hline \multirow{4}{*}{\multicolumn{2}{|c|}{$\begin{array}{r}\text { Outcome(s) } \\
\text { Predictor(s) } \\
\text { hesized Effect } \\
\text { vidence Type }\end{array}$}} & $\mathrm{AB}$ & $\mathrm{PB}$ & $\mathrm{AB}$ & $\mathrm{PB}$ & $\mathrm{AB}$ & PB & \multirow[b]{2}{*}{$\mathrm{OFO} / \mathrm{SFO}$} & \multirow[b]{2}{*}{$\mathrm{AB} / \mathrm{PB}$} \\
\hline & & SFO & SFO & OFO & OFO & $\mathrm{SFO} / \mathrm{OFO}$ & $\mathrm{SFO} / \mathrm{OFO}$ & & \\
\hline & & Positive & Positive & Negative & Positive & $\mathrm{H}_{3}>\mathrm{H}_{1}$ & $\mathrm{H}_{4}>\mathrm{H}_{2}$ & $.2>r<.5^{\mathrm{a}}$ & $0>r>-.5$ \\
\hline & & Est. & Est. & Est. & Est. & $\mathrm{H}_{3}: \mathrm{H}_{1}$ & $\mathrm{H}_{4}: \mathrm{H}_{2}$ & $r$ & $r$ \\
\hline $\begin{array}{l}\text { Study } \\
1\end{array}$ & Effects & $.12 *$ & $.17 *$ & $-0.19 *$ & .11 & $1.6^{\mathrm{b}}$ & $0.64^{b}$ & $.59 *$ & $.08^{*}$ \\
\hline Study & \multirow{2}{*}{$\begin{array}{l}\text { Fixed Effect } \\
\% \text { Countries with } \\
\text { predicted effect }^{\mathrm{c}} \\
\end{array}$} & $.13^{*}$ & .05 & $-.21 *$ & $.33 *$ & \multirow[t]{2}{*}{$1.6 * \mathrm{~b}$} & $6.9 * b$ & \multirow[t]{2}{*}{$.29 *$} & \multirow[t]{2}{*}{-.00} \\
\hline 2 & & 96 & 67 & 98 & 100 & & & & \\
\hline Study & Fixed Effect & $.08^{*}$ & $.15^{*}$ & $-.19 *$ & $.24 *$ & $2.3 * \mathrm{~b}$ & $1.6^{* \mathrm{~b}}$ & $.36^{*}$ & $.08^{*}$ \\
\hline 3 & $\begin{array}{l}\% \text { Countries with } \\
\text { effect }^{\mathrm{c}}\end{array}$ & 85 & 78 & 100 & 88 & & & & \\
\hline \multirow[t]{3}{*}{$\begin{array}{c}\text { Study } \\
4\end{array}$} & \multirow{3}{*}{$\begin{array}{l}\text { Average Effect of } \\
\text { Indices }^{\mathrm{d}} \\
\text { \% } \text { supporting tests }^{\mathrm{e}} \\
\text { Aggregate measures }^{\mathrm{f}}\end{array}$} & $.08^{d}$ & $.08^{d}$ & $-.19^{d}$ & $.31^{\mathrm{d}}$ & $2.4^{\mathrm{d}}$ & $3.9^{d}$ & $.34^{\mathrm{d}}$ & $-.08^{d}$ \\
\hline & & 50 & 42 & 72 & 92 & 63 & 38 & $61^{f}$ & $58^{\mathrm{g}}$ \\
\hline & & $.33^{*}$ & -.04 & $-.52 *$ & $.75^{*}$ & $1.6^{* \mathrm{~b}}$ & $19.6^{* b}$ & $.54^{*}$ & $-.39 *$ \\
\hline \multicolumn{2}{|c|}{ Conclusions } & $\begin{array}{l}\text { Strong } \\
\text { Support } \\
\left(\mathrm{H}_{1}\right)\end{array}$ & $\begin{array}{l}\text { Moderate } \\
\text { Support } \\
\left(\mathrm{H}_{2}\right)\end{array}$ & $\begin{array}{l}\text { Strong } \\
\text { Support } \\
\left(\mathrm{H}_{3}\right)\end{array}$ & $\begin{array}{l}\text { Strong } \\
\text { Support } \\
\left(\mathrm{H}_{4}\right)\end{array}$ & $\begin{array}{l}\text { Strong } \\
\text { Support } \\
\left(\mathrm{H}_{5}\right)\end{array}$ & $\begin{array}{l}\text { Strong } \\
\text { Support } \\
\left(\mathrm{H}_{6}\right)\end{array}$ & $\begin{array}{l}\text { Moderate } \\
\text { Support } \\
\left(\mathrm{H}_{7}\right)\end{array}$ & $\begin{array}{l}\text { Mixed } \\
\text { Support }\left(\mathrm{H}_{8}\right)\end{array}$ \\
\hline
\end{tabular}

Note. ${ }^{*}$ Significant effect. Bold font $=$ supports hypothesis. Underlined font $=$ conflicts with hypothesis. Grey font $=$ neither in clear support nor contradiction with hypothesis. $\mathrm{H}=$ hypothesis; $\mathrm{AB}=$ antisocial behaviour; $\mathrm{PB}=$ prosocial behaviour; $\mathrm{SFO}=$ self-focused orientations; $\mathrm{OFO}=$ other-focused orientations; $r=$ Pearson's bivariate correlation; Est. = standardized regression coefficient.

a This range of correlations was selected to exclude correlations that were either small (i.e., $r<.2)$ or large (i.e., > .5).

${ }^{b}$ Ratio of the effect size of $\mathrm{H}_{1}$ to $\mathrm{H}_{3}$ (or $\mathrm{H}_{2}$ to $\mathrm{H}_{4}$ ). Significance level is determined by looking for overlapping confidence intervals.

'Under the null hypothesis, the percentages are expected to be $50 \%$.

${ }^{\mathrm{d}}$ Because these are average effects of parameters across several statistical models, statistical significance varies across models.

${ }^{\mathrm{e}}$ Represents the number of tests for which a significant finding was found in the hypothesized direction.

${ }^{\text {f}}$ Percent of 36 correlations between .2 and .5 . Range $=-.16$ to $.63 ; 22 \%$ were below .2 , and $17 \%$ above .5 .

${ }^{g}$ Percent of 12 correlations between .0 and -.5. Range $=-.46$. to $.15 .42 \%$ were positive in value but tended to be very small.

Consequently, the distribution is likely centred around the high end of our hypothesized range in Study 4 (i.e., between $r=0$ and -.1).

${ }^{\mathrm{f}}$ Analyses involve latent variables derived from all items used to measure the four construct types. See Section 4.3.2 and Figure 3. 
important given the current prevalence of wide-scale movements focused on promoting selffocused orientations such as self-care, self-empowerment, and self-esteem (e.g., Baumeister et al., 2003; Silva, 2017; Warren, 1996). Consistent with the cautions of others (Baumeister et al., 2003), our findings reassert the risk for these movements to inadvertently increase antisocial behaviours.

In contrast, we can also consider creating interventions that seek to decrease antisocial behaviours by reducing self-focused orientations, but there remains risks this could unintentionally reduce prosocial behaviours. Consequently, general caution should be used when intervening on self-focused orientations, and interventionists should carefully evaluate impacts on both prosocial and antisocial behaviours.

Lastly, the degree of heterogeneity in our findings is notable, as it suggests the associations of self-focused orientations may not always follow the same trend. Future works should examine when and why the associations between self-focused orientations and prosocial/antisocial outcomes are positive versus negative-perhaps examining whether certain socio-political or cultural factors can account for cross-national differences in the association between the two types of behaviours.

In examining heterogeneity, it may be particularly useful to subdivide self-focused orientations into more specific subclasses. For example, one class may incorporate orientations focused on skill-building, personal mastery, self-improvement, and autonomy seeking. Each of these themes are contributors to well-adjusted psychological development (Ryan \& Deci, 2000; Dweck, 2008; Reis et al., 2000) and may be closely linked to certain altruistically focused tendencies. Indeed, in Schwartz's theory of values, self-direction values most directly capture these themes and are considered adjacent to self-transcendent values (e.g., universalism; 
Schwartz et al., 2012b). Further, personality maturation usually involves a shift towards becoming more other-focused over time (Bleidorn, 2015; Gouveia et al., 2015; Milfont et al., 2016; Walker \& Frimer, 2015), so it may be a natural extension of desires for personal growth to become a better, more altruistic individual. In our own studies, the self-focused orientations of achievement motivation and independent self-construal both reflect this category of self-focused orientations, and both showed adaptive patterns of associations whereby they predicted decreased antisocial behaviours and increased prosocial behaviours.

In direct contrast to this category, some self-focused orientations are more directly tied to acquiring resources, status, and dominance over others; that is, enhancing one's position within society, without seeking personal growth. This category may be generally associated with worse interpersonal outcomes. For example, self-interest and power motivation, as assessed in Study 4, each reflect these themes heavily and show clear positive associations to antisocial behaviour, along with clear negative associations to prosocial behaviour. These findings make sense when we consider that this category of self-focused orientations may be furthest from seeking the welfare of others. For example, in Schwartz's theory of values (Schwartz et al., 2012b), this category is best reflected in the values of power and achievement - the latter of which should not be likened to our measure of achievement motivation (akin to self-direction) and is conceptually closer to our measure of self-interest (both focus on achieving social markers of success). Importantly, such values are understood to be conceptually furthest from values such as selftranscendence (Schwartz et al., 2012b).

\subsection{How do Other-Focused Orientations Relate to Prosocial and Antisocial Behaviours} $\left(\mathbf{H}_{3}-\mathrm{H}_{4}\right)$ ?

Across all our studies, other-focused orientations had clear and consistent positive 
associations with prosocial behaviours, and clear and consistent negative associations with antisocial behaviours (supporting $\mathrm{H}_{3}$ and $\mathrm{H}_{4}$ ). These patterns were highly homogenous across countries (Studies $2 \& 3$ ) and when considering different indices of other-focused orientations and behaviours (Study 4). The small amount of heterogeneity we found in these patterns may suggest that other-focused orientations are a more homogeneous class of variables relative to self-focused orientations, at least in their associations to prosocial/antisocial behaviours.

Conceptually, however, just as self-focused motivations can be broken down into distinct categories, a similar dynamic could be present for other-focused orientations. Notably, we can draw a distinction between orientations that are inherently concerned with the wellbeing of others (e.g., compassion, self-transcendence values, other-interest; DeYoung et al., 2007; Gerbasi \& Prentice, 2013; Schwartz et al., 2012b) and those that are more concerned with interpersonal relationships and maintaining social cohesion (e.g., collectivism, conformity/tradition values, affiliation motivations; Hui \& Triandis, 1986; Schönbrodt \& Gerstenberg, 2012; Schwartz et al., 2012b). Although prosocial/antisocial behaviours can reflect ends for both categories (e.g., prosocial acts are essential to maintain orderly society and build deep interpersonal connections), this reasoning may be particularly true for the former, as acting prosocially/antisocially is often tantamount with impacting the welfare of others. Thus, we could expect that prosocial and antisocial behaviours would be most consistently and powerfully linked to this first category, and this is borne out in the pattern of results from Study 4. For instance, compassion and other-interest show consistent and substantial positive and negative associations to prosocial and antisocial behaviours; in contrast, factors like interdependent self-construal and affiliation motivation show effects in the same direction, but these are smaller and less frequently significant. 
Overall, interventions focused on increasing other-focused orientations may generally be promising in promoting prosocial behaviours while inhibiting antisocial behaviours. This may be particularly true of orientations that are inherently focused on the wellbeing of others. Currently, however, fewer social movements and programs focus on promoting other-focused than selffocused orientations. Given the possible risks of targeting self-focused orientations, there are likely to be benefits from devoting additional resources to develop and promote interventions to promote other-focused orientations (e.g., compassion-based training; Weng et al., 2013).

\subsection{Which Orientation has a Stronger Association with Prosocial and Antisocial Behaviours ( $\left.\mathbf{H}_{5}-\mathrm{H}_{6}\right)$ ?}

Hypotheses $\mathrm{H}_{5}$ and $\mathrm{H}_{6}$ state that prosocial and antisocial behaviours should be more strongly associated with other-focused than self-focused orientations. Unfortunately Study 1 was largely uninformative due to very large CIs. However, in studies 2, 3, and 4, the effects associated with other-focused orientations were consistently greater in magnitude on both prosocial and antisocial outcomes than the effects associated with self-focused orientations (supporting both $\mathrm{H}_{5}$ and $\mathrm{H}_{6}$ ).

These findings reinforce the suggestion that other-focused orientations might be more efficient targets for interventions than self-focused orientations. They also reinforce the notion that prosocial/antisocial behaviours are often more central to other-focused goals (i.e., are ends of themselves) than they are to self-focused orientations (to which they may only be means to achieving self-focused goals). That said, it is important to note that the ends-means distinction may reflect a dynamic continuum between these variables rather than a fixed dichotomy, and that the status of a behaviour can shift across contexts and time.

For example, prosocial behaviours in the workplace (i.e., OCB) have been consistently 
linked to improved workplace performance by employees and their teams (Podsakoff et al., 2009), an outcome that aligns with self-focused goals like career and achievement motivations. Although engaging in OCBs does not guarantee performance, the repeated observation of improved performance arising from OCBs could lead individuals to form strong mental associations between OCBs and fulfilling their career/achievement goals. Over time, this association may lead them to begin perceiving OCBs as tantamount to (i.e., ends for) the pursuit of career/achievement (through a process of means-goal fusion; Kruglanski et al., 2018). This may explain why, in Study 4, achievement motivation showed its strongest association to the outcome of OCB. A similar dynamic may also be at play to account for the strong association (in Study 4) between power motivation and aggression. Indeed, aggression is often understood as a method through which individuals express or seek power, and longitudinal studies have found power motivations and aggression to be mutually reinforcing (Benish-Weisman, 2015).

As implied previously, similar variations may also be at play for other-focused orientations. For example, we argued that most other-focused orientations are concerned with the welfare of others, and that this would lead prosocial behaviours to be pursued as ends. However, some constructs, like affiliation motives, are instead centrally concerned with building/maintaining (often surface-level) interpersonal relationships. For fulfilling these orientations, prosocial acts may serve more as means than ends, and this could account for how affiliation generally showed smaller associations to prosocial behaviour than other constructs.

Theoretically, the degree to which behaviours are used and perceived as means versus ends to achieve motivational goals may be a useful lens to understanding and predicting how different variables (even outside our studies) relate to social behaviour. For instance, we can apply this lens to the distinction between empathy and compassion, two states which predict 
prosocial behaviour, but through distinct motivational dynamics. On the one hand, empathy allows individuals to experience the emotions of others (Gilbert, 2015); from this, individuals often engage in prosocial behaviours as means to alleviate their own negative affect (Cialdini et al., 1987) or to increase their own positive affect (Telle \& Pfister, 2016), both of which are selffocused goals. On the other hand, compassion is an other-focused motivation, fundamentally concerned with caring for others (Gilbert, 2015); as such, prosocial acts may usually be ends to fulfil compassion. Consequently, we may predict that compassion is a stronger, more consistent, predictor of prosocial behaviour than empathy — an assertion that does have empirical backing (Chierchia \& Singer 2017).

\subsection{What is the Average Association Between Self-Focused and Other-Focused Orientations (H7), and Between Prosocial and Antisocial Behaviours ( $\left.\mathrm{H}_{7}-\mathrm{H}_{8}\right)$ ?}

It is well-established that self- and other-focused orientations are two distinct dimensions (De Dreu \& Nauta, 2009; Markus \& Kitayama, 1991); however, the average association between them remains to be fully ascertained, with researchers commonly reporting associations anywhere between $r=0$ to $r=.5$ (e.g., DeYoung et al., 2007; Gerbasi \& Prentice, 2013; Singelis 1994). In our findings, the correlations between measures of self- and other-focused orientations were generally in the range of .2 to $.5\left(\mathrm{H}_{7}\right)$, with the overall average across tests being around $r=$ .35. There was a decent amount of spread, but correlations spread relatively evenly above and below our expected range. These associations are in line with ideas that self-focused and otherfocused orientations can be mutually supportive, as well as with the idea that a general motivational factor - reflecting a general disposition to act in a goal-directed way-may contribute positively to both orientations (supporting views by authors such as: Batey et al., 2011; Borg \& Bardi, 2016; Gunnell \& Gaudreau, 2015). 
However, it is also possible that the positive correlation between the two orientations could be accounted for by response biases (e.g., acquiescence bias, social desirability) or some other common-method bias (i.e., all measures being self-reports). To examine this possibility, we used data from studies 1 and 4 to compute alternate SEM analyses (bi-factor models: e.g., Biderman et al., 2011; Gu et al., 2015; Motl \& DiStefano, 2002) in which a general factor was added to between all item-level indicators of self-focused and other-focused orientations. These models are reported in Section 5 of the supplemental materials. Our inferences remained largely unchanged. The two motivational orientations remained correlated at a similar magnitude $\left(\mathrm{H}_{7}\right)$, not only supporting our hypotheses but also the possible operation of a general motivational factor. Further the associations between the two motivational orientations and prosocial/antisocial behaviours $\left(\mathrm{H}_{1}\right.$ to $\left.\mathrm{H}_{4}\right)$ also remained similar across analyses, providing evidence that our findings are not reducible to response/methods-based biases. That said, given that our analyses still rely on self-reports, future research should evaluate these findings using alternate methods such as informant reports.

The idea that a general factor of motivation may exist is of particular interest to explore further as it relates to many discussions and debates that have spanned years in the personality domain surrounding the presence/absence of higher order factors (Bäckström et al., 2009; Chang et al., 2012; DeYoung 2015; Digman, 1997; Musek, 2007; Rushton et al., 2008; Van der Linden et al., 2010). Given that most broad personality traits like the Big 5 have motivational substrates (e.g., openness reflects dispositions towards gaining knowledge/experiences, and the Big 2 [agency/communion] are explicitly self- and other-focused orientations), it may be fruitful to examine whether correlations between broad traits arise due to a combination of a general motivational factor (e.g., accounting for covariance between motivationally-framed items) and 
methods factors (e.g., response biases accounting for more general covariance). In line with this idea, frameworks that posit two higher-order factors within the Big 5 often attribute explicitly motivational elements to such factors (e.g., pursuing stability [status quo] vs. plasticity [i.e., change]; DeYoung, 2015; DeYoung et al., 2002).

Finally, in our studies, the correlations between prosocial and antisocial behaviours ranged between -.46 and .15 , with an overall average across tests just above $r=-.10$. Most correlations were negative, but several were positive (although small). Given this spread of effect sizes, the typical association between these two types of behaviours may either be nil or at the low end of our anticipated range (i.e., $r$ between 0 and -.10). These results support the view that prosocial and antisocial behaviours should generally be treated as distinct rather than opposing factors - a conclusion in line with the works of many authors that precede us (Eron \& Huesmann, 1984; Card et al., 2008; Dalal, 2005; Duncan et al., 2002; Harris et al., 1996; Krueger et al., 2001).

\subsection{How Might Self-Focused and Other-Focused Orientations Affect Other Types of Behaviours?}

Our studies used measures that categorize behaviours as either prosocial or antisocial. However, our operational definitions of the two types of behaviours are not mutually exclusive; a behaviour could feasibly be both prosocial and antisocial. Behaviours at the intersection of prosociality and antisociality may be especially interesting domains for future research. For instance, consider people doing an action that harms members of an outgroup to help members of an ingroup. Here, we might expect a positive association with self-focused orientations (as ingroups are likely to reward their successful members), but the association with other-focused orientations may be more nuanced and varied according to the specific type of other-focused 
orientation considered. For example, orientations towards benefitting close others and ingroup members (e.g., collectivistic inclinations, intimacy motivations) could lead people to engage in such behaviours more frequently. Indeed, collectivistic values can accentuate ingroup-outgroup divides (Triandis, 1995), and biological processes tied to building/maintaining close relationships, such as the operation of oxytocin (Aguilar-Raab et al., 2019), similarly lead to both ingroup favouritism and outgroup competition/aggression (De Dreu, 2012; De Dreu et al., 2012). In contrast, other-focused orientations like self-transcendent values are associated with lower prejudice/discrimination towards outgroups (Feather \& McKee, 2008; Zibenberg, \& Kupermintz, 2016) and may lead people to withhold from such actions. For other behaviours at the intersection of prosociality/antisociality the reverse pattern may emerge. For example, we could expect extreme social activism to be promoted by a strong motivation for fairness, but inhibited by motives tied to maintaining social norms.

When behaviours have both prosocial and antisocial consequences, the time frame of the consequences could be another productive area to explore. For example, parents engaging in strict discipline, or having their children vaccinated, accept to commit short-terms harms (e.g., a harsh punishment, a painful shot) to achieve long-term benefits (e.g., good socialization, immunity to disease). Such behaviours are typically motivated by altruistic concerns for one's child. However, altruistic motives can also inhibit such behaviours. For example, wanting to protect children from the pain associated with getting shot-based vaccines is a common barrier to vaccination, even among parents who are aware of the long-term benefits (Mills et al., 2005). Future research should therefore clarify the pattern of associations between motivational orientations and behaviours that have both prosocial and antisocial elements.

In addition, it is worth considering how behaviours impact the self. That is, in addition to 
being defined in terms of benefits towards others (prosocial) and harms towards others (antisocial), behaviours can also be defined according to the degree to which they benefit ("proself” behaviours) and harm the self (“anti-self” behaviours). Generally, our hypotheses rested upon the idea that prosocial and antisocial behaviours are end goals for other-focused orientations, but usually means towards self-focused goals. If a similar logic holds generally, we could expect complementary associations for behaviours that obtain/avoid outcomes for the self. Specifically, people with high self-focused orientations should seek to engage in more frequent behaviours that benefit them personally, but fewer behaviours that are personally costly (both are ends to self-focused goals). People with high other-focused orientations, however, may engage in both types of behaviours to the extent that they can use these behaviours to increase benefits (or decrease harms) for others around them (i.e., use the behaviours as means). These ideas could be examined in future research and would have important implications for interventions and clinical work.

\subsection{What Might Interventions to Target Self-Focused and Other-Focused Orientations} Look Like?

Interventionists can employ different strategies to target self-focused and other-focused orientations to alter rates of prosocial and antisocial behaviours. They may seek to alter people's motivations, leverage pre-existing individual differences, or engage in a combination of these strategies. When choosing a strategy, interventionists should be mindful of the degree to which many motivational orientations are chronic individual differences.

For instance, differences in basic personality traits (e.g., communion and agency) and values (e.g., social-focus and personal-focus values) are each chronic and relatively stable individual differences (Vecchione et al., 2016; Wright et al., 2012). This may make them 
challenging targets for change, especially as people age. Consequently, interventions targeting trait-level individual differences could focus their efforts on earlier life stages (e.g., childhood) when personality and values are more malleable (Caspi et al., 2005; Roberts \& DelVecchio, 2000). That said, there is still substantial amounts of personality change that occurs throughout the lifespan (Caspi et al., 2005) and there is a growing literature on the development of clinical and digital interventions that can exert long-lasting change on personality among adults (Magidson et al., 2014; Roberts et al., 2017; Stieger et al., 2021). Interventionists with the means to deploy such interventions should consider them. In doing so, it may be worth exploring whether increasing chronic levels of other-focused orientations may be easier to accomplish than altering levels of self-focused orientations, as the former aligns with normal processes of maturation whereby people become more other-focused as they age (Bleidorn, 2015; Gouveia et al., 2015; Milfont et al., 2016; Walker \& Frimer, 2015).

However, there are also alternate strategies to directly targeting chronic, trait-level dispositions. Most chronic individual differences (e.g., personality traits) reflect long-standing averages with substantial levels of within-person variation (i.e., state-level change) across time and situations (Fleeson, 2001; 2007; Fleeson \& Jayawickreme, 2015; Jayawickreme et al., 2019). This variation has been largely attributed to fluctuations in daily goals and lower-order motivations (Church et al., 2013; Heller et al., 2007; McCabe \& Fleeson, 2012); consequently, using interventions to alter state-level motivations could be a feasible strategy over targeting trait-level constructs. Indeed, altering situations (e.g., via goal priming) to elicit state-level changes in personality, values, and goals is a well-documented strategy (Moskowitz \& Gesundheit, 2009; McNiel \& Fleeson, 2019), and has been previously applied to understand and change both prosocial and antisocial behaviours (de Medeiros \& Hattori, 2021; Todorov \& 
Bargh, 2002). Situational interventions are thus promising and could be deployed to target larger numbers of individuals at a time (e.g., targeting all who interact with a given space). It has also been theorized that the repeated activation of states (e.g., other-focused goals) should contribute to long lasting change in associated traits over time (e.g., overall communion or social focus values; Bardi \& Goodwin, 2011). This proposition has important implications and should be explored in future empirical works.

Finally, another type of strategy interventionists can consider is to appeal to individuals' pre-existing motivations (rather than changing people's motivations) to influence rates of prosocial and antisocial behaviours. For instance, functional message matching research holds that people are more likely to be persuaded to change their beliefs and behaviours when persuasive messages are constructed in ways that match (vs. mismatch) their personal values and motivations (Joyal-Desmarais, 2021). This technique has been applied in many domains, such as encouraging volunteerism (e.g., Clary \& Snyder, 1999), proenvironmental behaviours (e.g., Graham \& Abrahamse, 2017), and political decisions (e.g., Feinberg \& Willer, 2015). A recent systematic review and meta-analysis found that most types of behaviours can be changed using functional message matching, with effects sometimes persisting for months after an intervention (Joyal-Desmarais, 2020). Behavioural maintenance has also been argued to follow the functional principle, with people being more likely to continue engaging in a behaviour (e.g., volunteerism) to the extent that the behaviour reinforces their specific motivational preferences (Clary et al., 1992; 1998). For example, an other-focused person may be more likely to maintain their volunteerism to the degree that they see benefits for others arising from their actions. Although the goal of functional matching interventions is not generally to alter motivational orientations, there is growing theoretical and empirical works to suggest that the repeated satisfaction of 
motivations leads to a reinforcement of those motivations over time (e.g., Baumeister, 2016; Burkley et al., 2013; Prentice et al., 2019; Vohs \& Baumeister, 2008). For example, the more wealth and status people have, the more wealth and status they seek (Wang et al., 2018). Consequently, interventionists using functional matching principles should still be weary of the unintended consequences the repeated enactment of such interventions could have over time.

\subsection{Should Indices of Self-Focused and Other-Focused Orientations be Used Interchangeably?}

In this project, we argued that self-focused and other-focused orientations represent two higher order categories of motivation. We discussed literature (encapsulated in Table A1) which documents associations between self-focused and other-focused constructs from different frameworks (e.g., the Interpersonal Circumplex, basic values, self-construal), and noted that authors have frequently used measures from these frameworks as interchangeable indicators of these two broader motivational categories (e.g., Abele \& Wojciszke, 2014; Miyamoto et al., 2018; Trapnell \& Paulhus, 2012). Our findings, particularly from Study 4, provide important insights to this perspective.

For example, if measures of self-focused orientations assess a common construct (a general self-focused orientation), then these measures should be more highly correlated with one another than to measures of other-focused orientations. Similarly, if measures of other-focused orientations assess a common construct (a general other-focused orientation), then these measures should be more highly correlated with one another than to measures of self-focused orientations. This follows the logic of multitrait-multimethod matrices (Campbell \& Fiske, 1959). Correlations between measures of the same category are presented in the lower diagonal of Table A1; from these, we see that the average correlations among self-focused measures and 
among other-focused measures are both large ( $r=.53$ and .50 , respectively). In contrast, the average correlation across self-focused and other-focused measures is moderate $(r=.34$; see Table S28) — this latter correlation may actually be overestimated as many pairs of self-focused and other-focused constructs were assessed using the same instrument and may share additional methods variance (e.g., interdependent and independent self-construal were both assessed using the measure by Singelis, 1994). These findings support the notion that each construct can effectively be used to tap into higher-order differences in self-focused and other-focused orientations.

However, does this mean that measures, or "lower-order" constructs, within a category (e.g., self-focused) can be used interchangeably to assess one another (e.g., using independent self-construal as an index of assertiveness)? Probably not. In fact, our findings are critical of this practice and suggest that authors should generally avoid using these constructs as proxies for each other. First, although correlations within each category are relatively strong, averaging close to $r=.50$, this also means that there is only an average $25 \%$ overlap in variance. Second, and most importantly, we found considerable variation in the degree and direction of associations to external variables within self-focused and other-focused categories. For example, independent self-construal and self-interest predict prosocial and antisocial behaviours in opposite directions; consequently, using one as a proxy for the other could lead to highly misleading conclusions.

\subsection{Strengths, Limitations, and Generalizability}

We acknowledge that our studies do not allow us to draw strong causal inferences, as they were cross-sectional and observational. We did not complement our studies with laboratorybased experiments because, although these would allow for stronger causal inferences, experimental paradigms tend to be limited in their ability to examine a representative and 
ecologically valid sample of behaviours - especially antisocial behaviours (Ritter \& Eslea, 2005). Given the limitation of experimental work, we suggest that the use of longitudinal assessments in future research would be particularly useful to strengthen our inferences. This would establish the temporal ordering of the effects.

The current studies also have several strengths. First, our analyses examining the effects of self-focused orientations always controlled for the effects of other-focused orientations, and vice-versa. Given the frequent and non-trivial association between these two orientations, this allowed us to better isolate the relevant effects. Second, we built on past research by consistently examining the effects of these two orientations on prosocial and antisocial behaviours simultaneously. Such analyses afford a richer perspective on the breadth of effects associated with the predictors, allowing us to better capture possible side-effects that may be associated with changing the motivational orientations. Third, we used strong measurement models, especially in Study 4, to assess each predictor and outcome variable, allowing us to estimate patterns with higher reliability and validity. Fourth, we replicated our findings across four distinct samples, varying from American samples (Studies 1 and 4) to large samples drawn across 78 countries (Studies 2 and 3). These allowed us to examine the generalizability of our findings across diverse national contexts. Fifth, we examined many ways of operationalizing both our predictor and outcome variables. This provided us with greater confidence that our inferences could be drawn at a general and abstract level (i.e., about self-focused and otherfocused orientations in general), while also allowing us to observe variations across different operationalizations.

With relation to this last point, however, we advise caution when considering single associations between two specific indicators (e.g., interdependent self-construal and OCB). Such 
associations depend on single or small sets of tests and should be replicated. In contrast, we have more confidence in inferences that involve repeated tests of an association between any specific indicator and a general type of variable (e.g., interdependent self-construal and prosocial behaviours), as multiple tests of this association converge. Finally, we have the greatest confidence in the associations among the broad types of variables (e.g., other-focused orientations and prosocial behaviours). These broad inferences are, after all, the main questions the current project was designed to address.

\section{Conclusion}

This project advocates taking a more holistic view of the associations between broad psychological predictors of behaviours (i.e., self-focused and other-focused orientations) and multiple behavioural outcomes. Since past research on the psychological correlates of prosocial and antisocial behaviours have been relatively isolated from each other, we sought to bring these literatures together by considering both behaviour types simultaneously.

In four studies, we examined how individual differences in self- and other-focused orientations were associated with prosocial and antisocial behaviours/attitudes. We found consistent evidence that other-focused orientations were positively associated with prosocial outcomes and negatively associated with antisocial outcomes; effects were highly consistent cross-nationally and across different assessment methods. Additionally, we found self-focused orientations to generally be positively related to both prosocial and antisocial outcomes, but the association to prosocial behaviours varied substantially across nations and different operationalizations of self-focused orientations.

Our findings advise caution that targeting self-focused orientations to change behaviours (e.g., increasing prosocial behaviours) could have negative unintended consequences (e.g., 
increasing antisocial behaviours). Other-focused orientations may be more effective intervention targets and may even benefit from positive unintended effects (e.g., decreasing antisocial behaviours). 


\section{References}

Abele, A. E., Hauke, N., Peters, K., Louvet, E., Szymkow, A., \& Duan, Y. (2016). Facets of the fundamental content dimensions: Agency with competence and assertiveness - Communion with warmth and morality. Frontiers in Psychology, 7, Article 1810.

Abele, A. E., \& Wojciszke, B. (2007). Agency and communion from the perspective of self versus others. Journal of Personality and Social Psychology, 93, 751-763.

Abele, A. E., \& Wojciszke, B. (2014). Communal and agentic content in social cognition: A dual perspective model. In M. P. Zanna \& J. M. Olsen (Eds.) Advances in experimental social psychology (Vol. 50, pp. 195-255). Academic Press.

Adams, P. J., Towns, A., \& Gavey, N. (1995).

Dominance and entitlement: The rhetoric men use to discuss their violence towards women. Discourse \& Society, 6(3), 387-406.

Aguilar-Raab, C., Eckstein, M., Geracitano, S., Prevost, M., Gold, I., Heinrichs, M., Bilderbeck, A., Ehlert, U., \& Ditzen, B. (2019). Oxytocin modulates the cognitive appraisal of the own and others close intimate relationships. Frontiers in Neuroscience, 13,714 .

Albert, P. A., \& Thilagavathy, T. (2013). A study on relationship between anti social behaviour and socio-economic status of higher secondary students. Education, 2(12), 132-133.

Amato, P. R. (1990). Personality and social network involvement as predictors of helping behavior in everyday life. Social Psychology Quarterly, 53, 3143.

Anderson, C. A. (1987). Temperature and aggression: Effects on quarterly, yearly, and city rates of violent and nonviolent crime. Journal of personality and social psychology, 52, 1161-1173.

Anderson, C. A., \& Bushman, B. J. (2002). Human aggression. Annual Review of Psychology, 53(1), 2751.

Auster, C. J., \& Ohm, S. C. (2000). Masculinity and femininity in contemporary American society: A reevaluation using the Bem Sex-Role Inventory. Sex Roles, 43(7-8), 499-528.

Bäckström, M., Björklund, F., \& Larsson, M. R. (2009). Five-factor inventories have a major general factor related to social desirability which can be reduced by framing items neutrally. Journal of Research in Personality, 43(3), 335-344.

Bakan, D. (1966). The duality of human existence. An essay on psychology and religion. Oxford, England: Rand McNally.
Bandura, A. (1978). Social learning theory of aggression. Journal of Communication, 28, 1229.

Bardi, A., \& Goodwin, R. (2011). The dual route to value change: Individual processes and cultural moderators. Journal of Cross-Cultural Psychology, 42(2), 271-287.

Bardi, A., \& Schwartz, S. H. (2003). Values and behavior: Strength and structure of relations. Personality and Social Psychology Bulletin, 29(10), 1207-1220.

Barnes, J. C., \& Boutwell, B. B. (2013). A demonstration of the generalizability of twin-based research on antisocial behavior. Behavior Genetics, 43(2), 120-131.

Baron, R. A. (1971). Aggression as a function of audience presence and prior anger arousal. Journal of Experimental Social Psychology, 7, 515-523.

Bates, D., Mächler, M., Bolker, B., \& Walker, S. (2015). Fitting linear mixed-effects models using lme4. Journal of Statistical Software, 67, 1-48.

Bates, D., Mächler, M., Bolker, B., Walker, S., Christensen, R. H. B., Singmann, H., ... \& Grothendieck, G. (2018). Package 'Ime4'. $R$ package version 1.1-17.

Batey, M., Booth, T., Furnham, A., \& Lipman, H. (2011). The relationship between personality and motivation: Is there a general factor of motivation?. Individual Differences Research, 9(2).

Batson, C. D. (1987). Prosocial motivation: Is it ever truly altruistic? In L. Berkowitz (Ed.), Advances in experimental social psychology (Vol. 20, pp. 65122). San Diego, CA: Academic Press.

Batson, C.D. (1998). Altruism and prosocial behavior. In D. T. Gilbert, S. T. Fiske, \& G. Lindzey (Eds.), The handbook of social psychology (4th ed., Vol. 2, pp. 282-316). New York: McGraw-Hill.

Batson, C. D., \& Powell, A. A. (2003). Altruism and prosocial behavior. In T. Millon \& M. J. Lerner (Eds.), Handbook of Psychology: Personality and Social Psychology (Vol. 5, pp. 463-484). Hoboken, NJ: John Wiley \& Sons.

Baumeister, R. F. (2016). Toward a general theory of motivation: Problems, challenges, opportunities, and the big picture. Motivation and Emotion, 40(1), 110.

Baumeister, R. F., Campbell, J. D., Krueger, J. I., \& Vohs, K. D. (2003). Does high self-esteem cause better performance, interpersonal success, happiness, or healthier lifestyles? Psychological Science in the Public Interest, 4, 1-44. 
Baumeister, R. F., Smart, L., \& Boden, J. M. (1996). Relation of threatened egotism to violence and aggression: The dark side of high self-esteem. Psychological Review, 103, 5-33.

Beaver, K. M., Gibson, C. L., DeLisi, M., Vaughn, M. G., \& Wright, J. P. (2012). The interaction between neighborhood disadvantage and genetic factors in the prediction of antisocial outcomes. Youth Violence and Juvenile Justice, 10(1), 25-40.

Bem, S. L. (1974). The measurement of psychological androgyny. Journal of Consulting and Clinical Psychology, 42(2), 155.

Bem, S. L. (1981). Bem Sex Role Inventory: Professional manual. Palo Alto, CA: Consulting Psychologists Press, Inc.

Bem, S. L., Martyna, W., \& Watson, C. (1976). Sex typing and androgyny: Further explorations of the expressive domain. Journal of Personality and social Psychology, 34(5), 1016-1023.

Benish-Weisman, M. (2015). The interplay between values and aggression in adolescence: A longitudinal study. Developmental Psychology, 51(5), 677-687.

Benish-Weisman, M. (2019). What can we learn about aggression from what adolescents consider important in life? The contribution of values theory to aggression research. Child Development Perspectives, 13(4), 260-266.

Biderman, M. D., Nguyen, N. T., Cunningham, C. J., \& Ghorbani, N. (2011). The ubiquity of common method variance: The case of the Big Five. Journal of Research in Personality, 45(5), 417-429.

Bilsky, W., \& Schwartz, S. H. (2008). Measuring motivations: Integrating content and method. Personality and Individual Differences, 44(8), 17381751.

Bivand, R., Ono, H., Dunlap, R., \& Stigler, M. (2018). Package 'classInt'. R package version 0.2-3.

Bleidorn, W. (2015). What accounts for personality maturation in early adulthood?. Current Directions in Psychological Science, 24(3), 245-252.

Böhm, R., Rusch, H., \& Gürerk, Ö. (2016). What makes people go to war? Defensive intentions motivate retaliatory and preemptive intergroup aggression. Evolution and Human Behavior, 37(1), 29-34.

Borden, R. J., \& Taylor, S. P. (1973). The social instigation and control of physical aggression. Journal of Applied Social Psychology, 3, 354-361.

Borg, I., \& Bardi, A. (2016). Should ratings of the importance of personal values be centered?. Journal of Research in Personality, 63, 95-101.

Brunstein, J. C., Schultheiss, O. C., \& Grässman, R. (1998). Personal goals and emotional well-being: The moderating role of motive dispositions. Journal of Personality and Social Psychology, 75(2), 494508.

Buchanan, K., \& Bardi, A. (2015). The roles of values, behavior, and value-behavior fit in the relation of agency and communion to well-being. Journal of Personality, 83(3), 320-333.

Buller, D. B., \& Burgoon, J. K. (1996). Interpersonal deception theory. Communication theory, 6, 203242.

Burkley, E., Anderson, D., Curtis, J., \& Burkley, M. (2013). Vicissitudes of goal commitment: Satisfaction, investments, and alternatives. Personality and Individual Differences, 54(5), 663 668.

Buss, A. H. (1961). The psychology of aggression. Hoboken, NJ: John Wiley \& Sons.

Buss, A. H., \& Perry, M. P. (1992). The aggression questionnaire. Journal of Personality and Social Psychology, 63, 452-459.

Campbell, D. T., \& Fiske, D. W. (1959). Convergent and discriminant validation by the multitraitmultimethod matrix. Psychological Bulletin, 56(2), 81.

Card, N. A., Stucky, B. D., Sawalani, G. M., \& Little, T. D. (2008). Direct and indirect aggression during childhood and adolescence: A meta-analytic review of gender differences, intercorrelations, and relations to maladjustment. Child Development, 79, 11851229.

Carlo, G., Okun, M. A., Knight, G. P., \& de Guzman, M. R. T. (2005). The interplay of traits and motives on volunteering: Agreeableness, extraversion and prosocial value motivation. Personality and Individual Differences, 38, 1293-1305.

Carpenter, J., \& Myers, C. K. (2010). Why volunteer? Evidence on the role of altruism, image, and incentives. Journal of Public Economics, 94(11-12), 911-920.

Caspi, A., Roberts, B. W., \& Shiner, R. L. (2005). Personality development: Stability and change. Annual Review of Psychology, 56, 453-484.

Chalmers, R. P. (2012). mirt: A multidimensional item response theory package for the $\mathrm{R}$

environment. Journal of Statistical Software, 48, 1-29.

Chang, L., Connelly, B. S., \& Geeza, A. A. (2012).

Separating method factors and higher order traits of the Big Five: A meta-analytic multitraitmultimethod approach. Journal of Personality and Social Psychology, 102(2), 408-426.

Chierchia, G., \& Singer, T. (2017). The neuroscience of compassion and empathy and their link to prosocial motivation and behavior. In Decision neuroscience (pp. 247-257). Academic Press.

Chowdhry, P. (1997). Enforcing cultural codes: Gender and violence in northern India. Economic and Political Weekly, 1019-1028.

Chulef, A., Read, S., \& Walsh, D. (2001). A hierarchical taxonomy of human goals. Motivation and Emotion, 25(3), 191-232. 
Church, A. T., Katigbak, M. S., Ching, C. M., Zhang, H., Shen, J., Arias, R. M., Rincon, B. C., Morio, H., Tanaka-Matsumi, J., Takaoka, S., Mastor, K. A., Roslan, N. A., Ibáñez-Reyes, J., Vargas-Flores, J. d. J., Locke, K. D., Reyes, J. A. S., Wenmei, S., Ortiz, F. A., \& Alvarez, J. M. (2013). Within-individual variability in self-concepts and personality states: Applying density distribution and situation-behavior approaches across cultures. Journal of Research in Personality, 47(6), 922-935.

Cialdini, R. B., Schaller, M., Houlihan, D., Arps, K., Fultz, J., \& Beaman, A. L. (1987). Empathy-based helping: Is it selflessly or selfishly motivated? Journal of Personality and Social Psychology, 52(4), 749-758.

Clary, E. G., \& Snyder, M. (1999). The motivations to volunteer: Theoretical and practical considerations. Current Directions in Psychological Science, 8, 156159.

Clary, E. G., Snyder, M., \& Ridge, R. (1992). Volunteers' motivations: A functional strategy for the recruitment, placement, and retention of volunteers. Nonprofit Management and Leadership, 2(4), 333-350.

Clary, E. G., Snyder, M., Ridge, R. D., Copeland, J., Stukas, A. A., Haugen, J., \& Miene, P. (1998). Understanding and assessing the motivations of volunteers: a functional approach. Journal of Personality and Social Psychology, 74(6), 1516.

Connelly, C. E., Zweig, D., Webster, J., \& Trougakos, J. P. (2012). Knowledge hiding in organizations. Journal of Organizational Behavior, 33(1), 64-88.

Cross, S. E., \& Madson, L. (1997). Models of the self: Self-construals and gender. Psychological Bulletin, 122(1), 5-37.

Cukur, C. S., De Guzman, M. R. T., \& Carlo, G. (2004). Religiosity, values, and horizontal and vertical individualism - Collectivism: A study of Turkey, the United States, and the Philippines. The Journal of Social Psychology, 144(6), 613-634.

Dalal, R. S. (2005). A meta-analysis of the relationship between organizational citizenship behavior and counterproductive work behavior. Journal of Applied Psychology, 90, 1241-1255.

Datu, J. A. D. (2015). Validating the revised selfconstrual scale in the Philippines. Current Psychology, 34(4), 626-633.

De Dreu, C. K. (2012). Oxytocin modulates cooperation within and competition between groups: an integrative review and research agenda. Hormones and Behavior, 61(3), 419-428.

De Dreu, C. K., Greer, L. L., Van Kleef, G. A., Shalvi, S., \& Handgraaf, M. J. (2011). Oxytocin promotes human ethnocentrism. Proceedings of the National Academy of Sciences, 108(4), 1262-1266.

De Dreu, C. K. W., \& Nauta, A. (2009). Self-interest and other-orientation in organizational behavior: implications for job performance, prosocial behavior, and personal initiative. Journal of Applied Psychology, 94, 913-926.

De Groot, J. I., \& Steg, L. (2009). Morality and prosocial behavior: The role of awareness, responsibility, and norms in the norm activation model. The Journal of Social Psychology, 149, 425-449.

de Medeiros, M. W. A., Hattori, W. T., \& Yamamoto, M. E. (2021). Priming effects on prosocial behavior of children: A systematic review. Trends in Psychology, 1-18.

Denson, T. F., DeWall, C. N., \& Finkel, E. J. (2012). Self-control and aggression. Current Directions in Psychological Science, 21, 20-25.

Derryberry, D., \& Tucker, D. M. (1994). Motivating the focus of attention. In P. M. Niedenthal \& S.

Kitayama (Eds.), The heart's eye: Emotional influences in perception and attention (pp. 167196). Academic Press.

DeWall, C. N., Anderson, C. A., \& Bushman, B. J. (2012). Aggression. In H. Tennen, J. Suls, \& I. B. Weiner, (Eds.), Handbook of psychology (2nd ed., Vol. 5, pp. 449-466). Hoboken, NJ: John Wiley \& Sons.

DeWall, C. N., Baumeister, R. F., Gailliot, M. T., \& Maner, J. K. (2008). Depletion makes the heart grow less helpful: Helping as a function of self-regulatory energy and genetic relatedness. Personality and Social Psychology Bulletin, 34, 1653-1662.

DeYoung, C. G. (2015). Cybernetic big five theory. Journal of Research in Personality, 56, 33-58.

DeYoung, C. G., Quilty, L. C., \& Peterson, J. B. (2007). Between facets and domains: 10 aspects of the Big Five. Journal of Personality and Social Psychology, 93, 880-896.

DeYoung, C. G., Peterson, J. B. , \& Higgins, D. M. (2002). Higher-order factors of the Big Five predict conformity: Are there neuroses of health? Personality and Individual Differences, 33, 533552.

DeYoung, C. G., Weisberg, Y. J., Quilty, L. C., \& Peterson, J. B. (2013). Unifying the aspects of the Big Five, the interpersonal circumplex, and trait affiliation. Journal of Personality, 81, 465-475.

Di Dio, L., Saragovi, C., Koestner, R., \& Aubé, J. (1996). Linking personal values to gender. Sex Roles, 34(9-10), 621-636.

Diekman, A. B., \& Eagly, A. H. (2008). Of men, women, and motivation: A role congruity account. In J. Y. Shah \& W. L. Gardner (Eds.), Handbook of motivation science (p. 434-447). The Guilford Press.

Digman, J. M. (1997). Higher-order factors of the Big Five. Journal of Personality and Social Psychology, 
73, 1246-1256.

Dijksterhuis, A., \& Aarts, H. (2010). Goals, attention, and (un) consciousness. Annual Review of Psychology, 61, 467-490.

Donnelly, K., \& Twenge, J. M. (2017). Masculine and feminine traits on the Bem Sex-Role Inventory, 1993-2012: A cross-temporal meta-analysis. Sex Roles, 76(9), 556-565.

Dovidio, J. F., Piliavin, J. A., Schroeder, D. A., \& Penner, L. A. (2006). The social psychology of prosocial behavior. Hillsdale, NJ: Lawrence Erlbaum.

Duncan, S. C., Duncan, T. E., Strycker, L. A., \& Chaumeton, N. R. (2002). Relations between youth antisocial and prosocial activities. Journal of Behavioral Medicine, 25(5), 425-438.

Dweck, C. (2008). Mindset: The new psychology of success. New York, NY: Random House.

Eisenberg, N., \& Miller, P. A. (1987). The relation of empathy to prosocial and related behaviors. Psychological Bulletin, 101, 91-119.

Epstein, S. (1979). The stability of behavior: I. On predicting most of the people much of the time. Journal of Personality and Social Psychology, 37, 1097-1126.

Epstein, S. (1980). The stability of behavior: II. Implications for psychological research. American Psychologist, 35, 790-806.

Eron, L. D., \& Huesmann, L. R. (1984). The relation of prosocial behavior to the development of aggression and psychopathology. Aggressive Behavior, 10, 201-211.

Faragó, L., Kende, A., \& Krekó, P. (2019). Justification of intergroup violence-the role of right-wing authoritarianism and propensity for radical action. Dynamics of Asymmetric Conflict, 12(2), 113-128

Faul, F., Erdfelder, E., Buchner, A., \& Lang, A. G. (2009). Statistical power analyses using $\mathrm{G}^{*}$

Power 3.1: Tests for correlation and regression analyses. Behavior Research Methods, 41, 1149-1160.

Feather, N. T., \& McKee, I. R. (2008). Values and prejudice: Predictors of attitudes towards Australian Aborigines. Australian Journal of Psychology, 60(2), 80-90.

Feinberg, M., \& Willer, R. (2015). From gulf to bridge: When do moral arguments facilitate political influence?. Personality and Social Psychology Bulletin, 41(12), 1665-1681.

Felson, R. B. (1978). Aggression as impression management. Social Psychology, 41(3), 205-213.

Fetzer Institute (n.d.). Self Report Measures for Love and Compassion Research: Helping Others [PDF file]. Retrieved from:

fetzer.org/sites/default/files/images/stories/pdf/selfm easures /HELPING_OTHERS.pdf

Fleeson, W. (2001). Toward a structure- and process- integrated view of personality: Traits as density distributions of states. Journal of Personality and Social Psychology, 80(6), 1011-1027.

Fleeson, W. (2007). Situation-based contingencies underlying trait-content manifestation in behavior. Journal of Personality, 75(4), 825-862.

Fleeson, W., Malanos, A. B., \& Achille, N. M. (2002). An intraindividual process approach to the relationship between extraversion and positive affect: Is acting extraverted as" good" as being extraverted?. Journal of Personality and Social Psychology, 83(6), 1409.

Fleeson, W., \& Jayawickreme, E. (2015). Whole trait theory. Journal of Research in Personality, 56, 8292.

Fouad, N. A., Kantamneni, N., Smothers, M. K., Chen, Y. L., Fitzpatrick, M., \& Terry, S. (2008). Asian American career development: A qualitative analysis. Journal of Vocational Behavior, 72(1), 4359.

Freedman, M. B., Leary, T. F., Ossario, A. G., \& Coffey, H. S. (1951). The interpersonal dimension of personality. Journal of Personality, 20, 143-161.

Frimer, J.A., Walker, L., Dunlop, W.L., Lee, B.H., \& Riches, A. (2011). The integration of agency and communion in moral personality: Evidence of enlightened self-interest. Journal of Personality and Social Psychology, 101(1), 149-63.

Gaudreau, P. (1977). Factor analysis of the Bem SexRole Inventory. Journal of Consulting and Clinical Psychology, 45, 299-302.

Gerbasi, M. E. (2011). The self-and other-interest inventory: Measurement and validation of a conceptualization of distinct constructs (Publication No. 3458612) [Doctoral Dissertation, Princeton University]. ProQuest Dissertations Publishing.

Gerbasi, M. E., \& Prentice, D. A. (2013). The Self-and Other-Interest Inventory. Journal of Personality and Social Psychology, 105(3), 495.

Gilbert, P. (2015). The evolution and social dynamics of compassion. Social and Personality Psychology Compass, 9(6), 239-254.

Goetz, J. L., Keltner, D., \& Simon-Thomas, E. (2010). Compassion: An evolutionary analysis and empirical review. Psychological Bulletin, 136(3), 351-374.

Gomà-i-Freixanet, M. (1995). Prosocial and antisocial aspects of personality. Personality and Individual Differences, 19, 125-134.

Gouveia, V. V., Vione, K. C., Milfont, T. L., \& Fischer, R. (2015). Patterns of value change during the life span: Some evidence from a functional approach to values. Personality and Social Psychology Bulletin, 41(9), 1276-1290.

Graham, T., \& Abrahamse, W. (2017). Communicating the climate impacts of meat consumption: The effect of values and message framing. Global 
Environmental Change, 44, 98-108.

Greenslade, J. H., \& White, K. M. (2005). The prediction of above-average participation in volunteerism: A test of the theory of planned behavior and the volunteers functions inventory in older Australian adults. The Journal of Social Psychology, 145, 155-172.

Griskevicius, V., Tybur, J. M., \& Van den Bergh, B. (2010). Going green to be seen: Status, reputation, and conspicuous conservation. Journal of Personality and Social Psychology, 98, 392-404.

Grotevant, H. D., Van Dulmen, M. H., Dunbar, N., Nelson-Christinedaughter, J., Christensen, M., Fan, X., \& Miller, B. C. (2006). Antisocial behavior of adoptees and nonadoptees: Prediction from early history and adolescent relationships. Journal of Research on Adolescence, 16(1), 105-131.

Gu, H., Wen, Z., \& Fan, X. (2015). The impact of wording effect on reliability and validity of the Core Self-Evaluation Scale (CSES): A bi-factor perspective. Personality and Individual Differences, 83, 142-147.

Gunnell, K. E., \& Gaudreau, P. (2015). Testing a bifactor model to disentangle general and specific factors of motivation in self-determination theory. Personality and Individual Differences, 81, 35-40.

Guo, G., Roettger, M. E., \& Shih, J. C. (2007). Contributions of the DAT1 and DRD2 genes to serious and violent delinquency among adolescents and young adults. Human Genetics, 121(1), 125136.

Guo, Q., Sun, P., \& Li, L. (2018). Shyness and online prosocial behavior: A study on multiple mediation mechanisms. Computers in Human Behavior, 86, 18.

Gurtman, M. B. (2009). Exploring personality with the interpersonal circumplex. Social and Personality Psychology Compass, 3(4), 601-619.

Haase, H., \& LautenschlaGer, A. (2011). Career choice motivations of university students. International Journal of Business Administration, 2(1), 2.

Habashi, M. M., Graziano, W. G., \& Hoover, A. E. (2016). Searching for the prosocial personality: A Big Five approach to linking personality and prosocial behavior. Personality and Social Psychology Bulletin, 42(9), 1177-1192.

Halevy, N., Bornstein, G., \& Sagiv, L. (2008). "Ingroup love" and "out-group hate" as motives for individual participation in intergroup conflict: A new game paradigm. Psychological Science, 19, 405-411.

Harris, J.A., Rushton, J.P., Hampson, E., \& Jackson, D.N. (1996). Salivary testosterone and self-report aggressive and pro-social personality characteristics in men and women. Aggressive Behavior, 22, 321331.
Harris, K. M., Halpern, C. T., Whitsel, E., Hussey, J., Tabor, J., Entzel, P., \& Udry, J. R. (2009).

The National Longitudinal Study of Adolescent to Adult Health: Research Design [WWW document]. Retrieved from http://www.cpc.unc.edu/projects/addhealth/design. [dataset] Harris, K. M., \& Udry, J. R. (2014). National Longitudinal Study of Adolescent to Adult Health (Add Health), 1994-2008 [Public Use] (ICPSR 21600) [Dataset file]. Retrieved from https://doi.org/10.3886/ICPSR21600.v18

Heckhausen, J., \& Heckhausen, H. (2008). Motivation and action (2nd ed.). Cambridge University Press.

Heilbrun, A. B., \& Bailey, B. A. (1986). Independence of masculine and feminine traits:

Empirical exploration of a prevailing assumption. Sex Roles, 14(3-4), 105-122.

Helgeson, V. S. (1994). Relation of agency and communion to well-being: Evidence and potential explanations. Psychological Bulletin, 116(3), 412428.

Heller, D., Komar, J., \& Lee, W. B. (2007). The dynamics of personality states, goals, and wellbeing. Personality and Social Psychology Bulletin, 33(6), 898-910.

Henry, P. J., Sidanius, J., Levin, S., \& Pratto, F. (2005). Social dominance orientation, authoritarianism, and support for intergroup violence between the Middle East and America. Political Psychology, 26(4), 569584.

Hershcovis, M. S., Turner, N., Barling, J., Arnold, K. A., Dupré, K. E., Inness, M., . . . Sivanathan, N. (2007). Predicting workplace aggression: A meta-analysis. Journal of Applied Psychology, 92, 228-238.

Hiller, D. V., \& Philliber, W. W. (1985). Internal consistency and correlates of the Bem Sex Role Inventory. Social Psychology Quarterly, 48(4), 373380 .

Hirsh, J. B., Galinsky, A. D., \& Zhong, C.-B. (2011). Drunk, powerful, and in the dark: How general processes of disinhibition produce both prosocial and antisocial behavior. Perspectives on Psychological Science, 6, 415-427.

Hofer, J., Chasiotis, A., \& Campos, D. (2006). Congruence between social values and implicit motives: Effects on life satisfaction across three cultures. European Journal of Personality, 20(4), 305-324.

Hofstede, G. (1980). Culture's consequences: International differences in work-related values. Beverly Hills, CA: Sage.

Hofstede, G. (2011). Dimensionalizing cultures: The Hofstede model in context. Online readings in Psychology and Culture, 2(1), 8.

Howell, A. J., \& Buro, K. (2017). Other-oriented hope: 
Initial evidence of its nomological net. Personality and Individual Differences, 106, 104-110.

Hui, C., Law, K. S., \& Chen, Z. X. (1999). A structural equation model of the effects of negative affectivity, leader-member exchange, and perceived job mobility on in-role and extra-role performance: A Chinese case. Organizational Behavior and Human Decision Processes, 77, 3-21.

Hui, C. H., \& Triandis, H. C. (1986). Individualismcollectivism a study of cross-cultural researchers. Journal of Cross-Cultural Psychology, 17(2), 225248.

Husain, M., \& Roiser, J. P. (2018). Neuroscience of apathy and anhedonia: a transdiagnostic approach. Nature Reviews Neuroscience, 19(8), 470-484.

Inglehart, R., C. Haerpfer, A. Moreno, C. Welzel, K. Kizilova, J. Diez-Medrano, M. Lagos, P. Norris, E. Ponarin \& B. Puranen et al. (eds.). 2014a. World Values Survey: Round Five - Country-Pooled Datafile 2005-2008. Madrid: JD Systems Institute. Version:

http://www.worldvaluessurvey.org/WVSDocumenta tionWV5.jsp

Inglehart, R., C. Haerpfer, A. Moreno, C. Welzel, K. Kizilova, J. Diez-Medrano, M. Lagos, P. Norris, E. Ponarin \& B. Puranen et al. (eds.). 2014b. World Values Survey: Round Six - Country-Pooled Datafile 2010-2014. Madrid: JD Systems Institute. Version:

http://www.worldvaluessurvey.org/WVSDocumenta tionWV6.jsp

James, J. B., Lewkowicz, C., Libhaber, J., \& Lachman, M. (1995). Rethinking the gender identity crossover hypothesis: A test of a new model. Sex Roles, 32(34), 185-207.

Jayawickreme, E., Zachry, C. E., \& Fleeson, W. (2019). Whole trait theory: An integrative approach to examining personality structure and process. Personality and individual Differences, 136, 2-11.

Jolliffe, D., \& Farrington, D. P. (2004). Empathy and offending: A systematic review and metaanalysis. Aggression and Violent Behavior, 9, 441476.

Jones, S. E., Miller, J. D., \& Lynam, D. R. (2011). Personality, antisocial behavior, and aggression: A meta-analytic review. Journal of Criminal Justice, 39, 329-337.

Josephs, R. A., Markus, H. R., \& Tafarodi, R. W. (1992). Gender and self-esteem. Journal of Personality and Social Psychology, 63(3), 391-402.

Joyal-Desmarais, K. (2020). When and How Do Message Matching Interventions Work? Exploring Principles to Guide the Use of Message Matching Through a Systematic Review and Meta-analysis, and an Experimental Study. [dissertation].

Joyal-Desmarais, K., Euh, H., Bai, H., Fleck, C.,
Johnson, W., Vitriol, J. A., Maki, A., \& Snyder, M. (2018, June). Why do some individuals oppose helping others? Exploring the underlying structure of anti-helping reasons. Poster presented at the 29th International Congress of Applied Psychology. Montreal, Canada. Retrieved from: https://osf.io/bsfwx/

[dataset] Joyal-Desmarais, K., Euh, H., Scharmer, A., \& Snyder, M. (2019, October 11). Examining the Role of Self- and Other-Focused Orientations and Motivational Correlates of Prosocial and Antisocial Behaviors. [Dataset file]. Available from: https://doi.org/10.17605/OSF.IO/FWYPT

Joyal-Desmarais, K., Rothman, A. J., \& Snyder, M. (2020). How do we optimize message matching interventions? Identifying matching thresholds, and simultaneously matching to multiple characteristics. European Journal of Social Psychology, 50(3), 701720.

Kemmelmeier, M., \& Oyserman, D. (2001). Gendered influence of downward social comparisons on current and possible selves. Journal of Social Issues, 57(1), 129-148.

Kempes, M., Matthys, W., De Vries, H., \& Van Engeland, H. (2005). Reactive and proactive aggression in children. A review of theory, findings and the relevance for child and adolescent psychiatry. European Journal of Psychiatry, 14, 1119.

Kitayama, S., Karasawa, M., Curhan, K. B., Ryff, C. D., \& Markus, H. R. (2010). Independence and interdependence predict health and wellbeing: Divergent patterns in the United States and Japan. Frontiers in Psychology, 1, 163.

Kitayama, S., Karasawa, M., Grossmann, I., Na, J., Varnum, M. E. W., PhD, \& Nisbett, R. (2019, October 28). East-West differences in cognitive style and social orientation: Are they real?. PsyArXiv. https://doi.org/10.31234/osf.io/c57ep

Konrath, S., \& Handy, F. (2020). The Good-looking Giver Effect: The relationship betweendoing good and looking good. Nonprofit and Voluntary Sector Quarterly, 1-29.

Krueger, R. F., Hicks, B. M., \& McGue, M. (2001). Altruism and antisocial behavior: Independent tendencies, unique personality correlates, distinct etiologies. Psychological Science, 12, 397402.

Kruglanski, A. W., Fishbach, A., Woolley, K., Bélanger, J. J., Chernikova, M., Molinario, E., \& Pierro, A. (2018). A structural model of intrinsic motivation: On the psychology of means-ends fusion. Psychological Review, 125(2), 165.

Kurz, T., Gardner, B., Verplanken, B., \& Abraham, C. (2015). Habitual behaviors or patterns of practice? Explaining and changing repetitive climate-relevant actions. Wiley Interdisciplinary Reviews: Climate 
Change, 6(1), 113-128.

Kuznetsova, A., Brockhoff, P. B., \& Christensen, R. H. B. (2017). lmerTest package: tests in linear mixed effects models. Journal of Statistical Software, $82(13)$.

Lambe, S., Hamilton-Giachritsis, C., Garner, E., \& Walker, J. (2018). The role of narcissism in aggression and violence: A systematic review. Trauma, Violence, \& Abuse, 19, 209-230.

Latané, B., \& Darley, J. M. (1968). Group inhibition of bystander intervention in emergencies. Journal of Personality and Social Psychology, 10(3), 215.

Leary, T. (1957). Interpersonal diagnosis of personality; a functional theory and methodology for personality evaluation. Ronald Press.

Leonard, R. (1997). Theorizing the relationship between agency and communion. Theory \& Psychology, 7(6), 823-835.

Lippa, R. (2001). On deconstructing and reconstructing masculinity-femininity. Journal of Research in Personality, 35, 168-207.

Locke, K. D. (2000). Circumplex scales of interpersonal values: Reliability, validity, and applicability to interpersonal problems and personality disorders. Journal of Personality assessment, 75(2), 249-267.

Loeber, R., \& Hay, D. (1997). Key issues in the development of aggression and violence from childhood to early adulthood. Annual Review of Psychology, 48, 371-410.

Long, M., \& Burke, R. H. (2015). The pro-social political vandal. In Vandalism and Anti-Social Behaviour (pp. 151-167). Palgrave Macmillan, London.

Magidson, J. F., Roberts, B. W., Collado-Rodriguez, A., \& Lejuez, C. W. (2014). Theory-driven intervention for changing personality: expectancy value theory, behavioral activation, and conscientiousness. Developmental Psychology, 50(5), 1442.

Mansfield, E. D., \& McAdams, D. P. (1996). Generativity and themes of agency and communion in adult autobiography. Personality and Social Psychology Bulletin, 22(7), 721-731.

Markus, H. R., \& Kitayama, S. (1991). Culture and the self: Implications for cognition, emotion, and motivation. Psychological Review, 98(2), 224-253.

McAdams, D. P., \& Constantian, C. A. (1983). Intimacy and affiliation motives in dailyliving: An experience sampling analysis. Journal of Personality and Social Psychology, 45, 851-861. http://dx.doi.org/10.1037/0022-3514.45.4.851.

McCabe, K. O., \& Fleeson, W. (2012). What is extraversion for? Integrating trait and motivational perspectives and identifying the purpose of extraversion. Psychological Science, 23(12), 14981505.

McNiel, J. M., \& Fleeson, W. (2006). The causal effects of extraversion on positive affect and neuroticism on negative affect: Manipulating state extraversion and state neuroticism in an experimental approach. Journal of Research in Personality, 40(5), 529-550.

Meglino, B. M., \& Korsgaard, A. (2004). Considering rational self-interest as a disposition: Organizational implications of other orientation. Journal of Applied Psychology, 89, 946-959.

Milfont, T. L., Milojev, P., \& Sibley, C. G. (2016). Values stability and change in adulthood: A 3-year longitudinal study of rank-order stability and meanlevel differences. Personality and Social Psychology Bulletin, 42(5), 572-588.

Miller, J. D., \& Lynam, D. (2001). Structural models of personality and their relation to antisocial behavior: A meta-analytic review. Criminology, 39, 765-798.

Mills, J. F., Anderson, D., \& Kroner, D. G. (2004). The antisocial attitudes and associates of sex offenders. Criminal Behaviour and Mental Health, 14(2), 134145.

Mills, E., Jadad, A. R., Ross, C., \& Wilson, K. (2005). Systematic review of qualitative studies exploring parental beliefs and attitudes toward childhood vaccination identifies common barriers to vaccination. Journal of Clinical Epidemiology, 58(11), 1081-1088.

Miyamoto, Y., Yoo, J., Levine, C. S., Park, J., Boylan, J. M., Sims, T., ... \& Coe, C. L. (2018). Culture and social hierarchy: Self-and other-oriented correlates of socioeconomic status across cultures. Journal of Personality and Social Psychology, 115(3), 427.

Moskowitz, G. B., \& Gesundheit, Y. (2009). Goal priming. In G. B. Moskowitz \& H. Grant (Eds.), The psychology of goals (pp. 203-233). Guilford Press.

Motl, R. W., \& DiStefano, C. (2002). Longitudinal invariance of self-esteem and method effects associated with negatively worded items. Structural Equation Modeling, 9(4), 562-578.

Mueller, D. J., \& Wornhoff, S. A. (1990). Distinguishing personal and social values. Educational and Psychological Measurement, 50, 691-699.

Musek, J. (2007). A general factor of personality: Evidence of the Big One in the five-factor model. Journal of Research in Personality, 41, 1213-1233.

Nagin, D. S., \& Pogarsky, G. (2003). An experimental investigation of deterrence: Cheating, self-serving bias, and impulsivity. Criminology, 41, 167-194.

Neff, K. D., \& Pommier, E. (2013). The relationship between self-compassion and other-focused concern among college undergraduates, community adults, and practicing meditators. Self and Identity, 12(2), 160-176.

Neuwirth, E. (2011). Package 'RColorBrewer'. R package version 1.1-2. 
Nickell, G. S. (1998). The helping attitude scale. Paper presented at the 106th Annual Convention of the American Psychological Association, San Francisco, USA.

Oishi, S., Schimmack, U., Diener, E., \& Suh, E. M. (1998). The measurement of values and individualism-collectivism. Personality and Social Psychology Bulletin, 24(11), 1177-1189.

Omoto, A. M., \& Snyder, M. (1995). Sustained helping without obligation: Motivation, longevity of service, and perceived attitude change among AIDS volunteers. Journal of Personality and Social Psychology, 68, 671-686.

Organ, D. W., \& Ryan, K. (1995). A meta-analytic review of attitudinal and dispositional predictors of organizational citizenship behavior. Personnel Psychology, 48(4), 775-802.

Ouellette, J. A., \& Wood, W. (1998). Habit and intention in everyday life: The multiple processes by which past behavior predicts future behavior. Psychological Bulletin, 124(1), 54-74.

Papies, E. K. (2016). Goal priming as a situated intervention tool. Current Opinion in Psychology, $12,12-16$.

Parboteeah, K. P., Cullen, J. B., \& Lim, L. (2004). Formal volunteering: A cross-national test. Journal of World Business, 39, 431-441.

Parks-Leduc, L., Feldman, G., \& Bardi, A. (2015). Personality traits and personal values: A metaanalysis. Personality and Social Psychology Review, 19(1), 3-29.

Podsakoff, P. M., MacKenzie, S. B., Moorman, R. H., \& Fetter, R. (1990). Transformational leader behaviors and their effects on followers' trust in leader, satisfaction, and organizational citizenship behaviors. The Leadership Quarterly, 1, 107-142.

Podsakoff, N. P., Whiting, S. W., Podsakoff, P. M., \& Blume, B. D. (2009). Individual-and organizationallevel consequences of organizational citizenship behaviors: A meta-analysis. Journal of Applied Psychology, 94(1), 122.

Pöhlmann, K. (2001). Agency- and communionorientation in life goals: Impacts on goal pursuit strategies and psychological well-being. In P. Schmuck \& K. M. Sheldon (Eds.), Life goals and well-being: Towards a positive psychology of human striving (p. 68-84). Hogrefe \& Huber Publishers.

Ponikiewska, K., Cieciuch, J., \& Strus, W. (2020). In search of convergence between the main dimensions of interpersonal and basic human values in the context of personality traits. Personality and Individual Differences, 162, 110003.

Porath, C. L., \& Erez, A. (2007). Does rudeness really matter? The effects of rudeness on task performance and helpfulness. Academy of Management Journal,
50, 1181-1197.

Prentice, M., Jayawickreme, E., \& Fleeson, W. (2019). Integrating whole trait theory and self-determination theory. Journal of Personality, 87(1), 56-69.

$\mathrm{R}$ Core Team. $R$ : A language and environment for statistical computing [computer program]. Vienna, Austria: R Foundation for Statistical Computing, 2017.

Rauthmann, J. F., Gallardo-Pujol, D., Guillaume, E. M., Todd, E., Nave, C. S., Sherman, R. A.,

Ziegler, M., Jones, A. B., \& Funder, D. C. (2014). The Situational Eight DIAMONDS: A taxonomy of major dimensions of situation characteristics. Journal of Personality and Social Psychology, 107(4), 677

Reis, H. T., Sheldon, K. M., Gable, S. L., Roscoe, J., \& Ryan, R. M. (2000). Daily well-being: The role of autonomy, competence, and relatedness. Personality and Social Psychology Bulletin, 26, 419-435.

Ritter, D., \& Eslea, M. (2005). Hot sauce, toy guns, and graffiti: A critical account of current laboratory aggression paradigms. Aggressive Behavior, 31, 407-419.

Roberts, B. W., \& DelVecchio, W. F. (2000). The rankorder consistency of personality traits from childhood to old age: A quantitative review of longitudinal studies. Psychological Bulletin, 126(1), $3-25$.

Roberts, B. W., Luo, J., Briley, D. A., Chow, P. I., Su, R., \& Hill, P. L. (2017). A systematic review of personality trait change through intervention. Psychological Bulletin, 143(2), 117-141.

Rosseel, Y. (2012). lavaan: An R package for structural equation modeling. Journal of Statistical Software, 48, 1-36.

Rothstein, S. I., \& Pierotti, R. (1988). Distinctions among reciprocal altruism, kin selection, and cooperation and a model for the initial evolution of beneficent behavior. Ethology and Sociobiology, 9(2-4), 189-209.

Rudnev, M., Magun, V., \& Schwartz, S. (2018). Relations among higher order values around the world. Journal of Cross-Cultural Psychology, 49(8), 1165-1182.

Rushton, J. P., Bons, T. A., \& Hur, Y. M. (2008). The genetics and evolution of the general factor of personality. Journal of Research in Personality, 42(5), 1173-1185.

Rushton, J. P., Chrisjohn, R. D., \& Fekken, G. C. (1981). The altruistic personality and the selfreport altruism scale. Personality and Individual Differences, 2, 293-302.

Ryan, R. M., \& Deci, E. L. (2000). Intrinsic and extrinsic motivations: Classic definitions and new directions. Contemporary Educational Psychology, 25(1), 54-67. 
Saragovi, C., Koestner, R., Di Dio, L., \& Aubé, J. (1997). Agency, communion, and well-being: Extending Helgeson's (1994) model. Journal of Personality and Social Psychology, 73(3), 593-609.

Seddig, D., \& Davidov, E. (2018). Values, attitudes toward interpersonal violence, and interpersonal violent behavior. Frontiers in Psychology, 9, 604.

Schaller, M., \& Cialdini, R. B. (1988). The economics of empathic helping: Support for a mood management motive. Journal of Experimental Social Psychology, 24(2), 163-181.

Schönbrodt, F. D., \& Gerstenberg, F. X. (2012). An IRT analysis of motive questionnaires: The Unified Motive Scales. Journal of Research in Personality, 46, 725-742.

Schroeder, D. A., Dovidio, J. F., Sibicky, M. E., Matthews, L. L., \& Allen, J. L. (1988). Empathic concern and helping behavior: Egoism or altruism?. Journal of Experimental Social Psychology, 24(4), 333-353.

Schroeder, D. A., \& Graziano, W. G. (Eds.). (2015). The Oxford handbook of prosocial behavior. New York, NY: Oxford University Press.

Schwartz, S. H. (1994a). Are there universal aspects in the structure and contents of human values? Journal of Social Issues, 50, 19-45.

Schwartz, S. H. (1994b). Beyond individualism/collectivism: New cultural dimensions of values.

In U. Kim, H. C. Triandis, Ç. Kâğitçibaşi, S.-C. Choi, \& G. Yoon (Eds.), Cross-cultural research and methodology series, Vol. 18. Individualism and collectivism: Theory, method, and applications ( $\mathrm{p}$. 85-119). Sage Publications, Inc.

Schwartz, S. H. (2012). An overview of the Schwartz theory of basic values. Online readings in Psychology and Culture, 2(1), 2307-0919.

Schwartz, S. H., \& Bilsky, W. (1987). Toward a universal psychological structure of human values. Journal of Personality and Social Psychology, 53(3), 550-562.

Schwartz, S. H., \& Boehnke, K. (2004). Evaluating the structure of human values with confirmatory factor analysis. Journal of Research in Personality, 38(3), 230-255.

Schwartz, S. H., Cieciuch, J., Vecchione, M., Davidov, E., Fischer, R., Beierlein, C., . . Konty, M. (2012a). Portrait Values Questionnaire 5X Value Survey (PVQ5X Value Survey), 2012. Retrieved from PsycTests. doi: 10.1037/t21484-000

Schwartz, S. H., Cieciuch, J., Vecchione, M., Davidov, E., Fischer, R., Beierlein, C., . . .

Demirutku, K. (2012b). Refining the theory of basic individual values. Journal of Personality and Social Psychology, 103, 663-688.

Schwartz, S. H., \& Rubel, T. (2005). Sex differences in value priorities: Cross-cultural and multimethod studies. Journal of Personality and Social Psychology, 89(6), 1010-1028.

Schwartz, S. H., \& Rubel-Lifschitz, T. (2009). Crossnational variation in the size of sex differences in values: Effects of gender equality. Journal of Personality and Social Psychology, 97(1), 171-185.

Silva, C. (2017). The Millennial obsession with selfcare. National Public Radio. Retrieved from: https://www.npr.org/2017/06/04/531051473/themillennial-obsession-with-self-care

Simpson, B., \& Willer, R. (2008). Altruism and indirect reciprocity: The interaction of person and situation in prosocial behavior. Social Psychology Quarterly, 71(1), 37-52.

Singelis, T. M. (1994). The measurement of independent and interdependent self-construals. Personality and Social Psychology Bulletin, 20, 580591.

Skimina, E., Cieciuch, J., Schwartz, S. H., Davidov, E., \& Algesheimer, R. (2019). Behavioral signatures of values in everyday behavior in retrospective and real-time self-reports. Frontiers in Psychology, 10, 281.

Snyder, M., \& Dwyer, P. (2012). Altruism and prosocial behavior. In H. Tennen, J. Suls, \& I. B. Weiner, (Eds.), Handbook of psychology (2nd ed., Vol. 5, pp. 467-485). Hoboken, NJ: John Wiley \& Sons.

Spector, P. E., Fox, S., Penney, L. M., Bruursema, K., Goh, A., \& Kessler, S. (2006). The dimensionality of counterproductivity: Are all counterproductive behaviors created equal? Journal of Vocational Behavior, 68, 446-460.

Sokolowski, K. (2008). Social bonding: Affiliation motivation and intimacy motivation. In J.

Heckhausen \& H. Heckhausen (Eds.), Motivation and action (2nd ed., pp. 184-201). Cambridge University Press.

Sokolowski, K., Schmalt, H. D., Langens, T. A., \& Puca, R. M. (2000). Assessing achievement, affiliation, and power motives all at once: The Multi-Motive Grid (MMG). Journal of Personality Assessment, 74, 126-145. http://dx.doi.org/10.1207/S15327752JPA740109.

South, A. (2011). rworldmap: A new R package for mapping global data. The R Journal, 3, 35-43.

Stieger, M., Flückiger, C., Rüegger, D., Kowatsch, T., Roberts, B. W., \& Allemand, M. (2021). Changing personality traits with the help of a digital personality change intervention. Proceedings of the National Academy of Sciences, 118(8).

South, A. (2016). Package 'rworldmap'. R package version 1.3-6.

Swanson, M. C. J., Bland, R. C., \& Newman, S. C. (1994). Antisocial personality disorders. Acta Psychiatrica Scandinavica, 89, 63-70. 
Telle, N. T., \& Pfister, H. R. (2016). Positive empathy and prosocial behavior: A neglected link. Emotion Review, 8(2), 154-163.

Todorov, A., \& Bargh, J. A. (2002). Automatic sources of aggression. Aggression and Violent Behavior, 7(1), 53-68.

Trapnell, P. D., \& Paulhus, D. L. (2012). Agentic and communal values: Their scope and measurement. Journal of Personality Assessment, 94(1), 39-52.

Trapnell, P. D., \& Wiggins, J. S. (1990). Extension of the interpersonal adjective scales to include the big five dimensions of personality. Journal of Personality and Social Psychology, 59(4), 781.

Triandis, H. C. (1995). Individualism and collectivism. Westview Press.

Triandis, H. C. (2001). Individualism-collectivism and personality. Journal of Personality, 69(6), 907-924.

Triandis, H. C., Leung, K., Villareal, M. J., \& Clack, F. I. (1985). Allocentric versus idiocentric tendencies: Convergent and discriminant validation. Journal of Research in Personality, 19(4), 395-415.

Triandis, H. C., McCusker, C., \& Hui, C. H. (1990). Multimethod probes of individualism and

collectivism. Journal of Personality and Social Psychology, 59(5), 1006-1020.

Twenge, J. M. (1997). Changes in masculine and feminine traits over time: A meta-analysis. Sex Roles, 36(5-6), 305-325.

Van der Linden, D., te Nijenhuis, J., \& Bakker, A. B. (2010). The general factor of personality: A metaanalysis of Big Five intercorrelations and a criterionrelated validity study. Journal of Research in Personality, 44(3), 315-327.

Vecchione, M., Schwartz, S., Alessandri, G., Döring, A. K., Castellani, V., \& Caprara, M. G. (2016). Stability and change of basic personal values in early adulthood: An 8-year longitudinal study. Journal of Research in Personality, 63, 111-122.

Verplanken, B., \& Aarts, H. (1999). Habit, attitude, and planned behaviour: is habit an empty construct or an interesting case of goal-directed automaticity?. European Review of Social Psychology, 10(1), 101134.

Verplanken, B., Trafimow, D., Khusid, I. K., Holland, R. W., \& Steentjes, G. M. (2009). Different selves, different values: Effects of self-construals on value activation and use. European Journal of Social Psychology, 39(6), 909-919.

Vize, C. E., Miller, J. D., \& Lynam, D. R. (2018). FFM facets and their relations with different forms of antisocial behavior: An expanded meta-analysis. Journal of Criminal Justice, 57, 67-75.

Vohs, K. D., \& Baumeister, R. F. (2008). Can satisfaction reinforce wanting? A new theory about long-term changes in strength of motivation. Handbook of Motivation Science, 373-389.
Walker, L. J., \& Frimer, J. A. (2015). Developmental trajectories of agency and communion in moral motivation. Merrill-Palmer Quarterly, 61(3), 412439.

Walker, A. J., Pratt, C. C., \& Eddy, L. (1995). Informal caregiving to aging family members: A critical review. Family Relations, 44, 402-411.

Wang, Z., Jetten, J., \& Steffens, N. K. (2020). The more you have, the more you want? Higher social class predicts a greater desire for wealth and status. European Journal of Social Psychology, 50(2), 360375.

Wang, Y., \& Wang, L. (2016). Self-construal and creativity: The moderator effect of self-esteem. Personality and Individual Differences, 99, 184-189.

Ward, L. C., Thorn, B. E., Clements, K. L., Dixon, K. E., \& Sanford, S. D. (2006). Measurement of agency, communion, and emotional vulnerability with the Personal Attributes Questionnaire. Journal of Personality Assessment, 86(2), 206-216.

Warren, J. (1996). Self-Esteem Movement Gains Mainstream Respect. Los Angeles Times. Retrieved from: http://articles.latimes.com/1996-0212/news/mn-35114_1_self-esteem-movement

Weisberg, Y. J., DeYoung, C. G., \& Hirsh, J. B. (2011). Gender differences in personality across the ten aspects of the Big Five. Frontiers in Psychology, 2, 178.

Weng, H. Y., Fox, A. S., Shackman, A. J., Stodola, D. E., Caldwell, J. Z., Olson, M. C., Rogers, G. M. \& Davidson, R. J. (2013). Compassion training alters altruism and neural responses to suffering. Psychological Science, 24(7), 1171-1180.

Wicker, F. W., Lambert, F. B., Richardson, F. C., \& Kahler, J. (1984). Categorical goal hierarchies and classification of human motives. Journal of Personality, 52(3), 285-305.

Wiggins, J. S. (1996). An informal history of the interpersonal circumplex tradition. Journal of Personality Assessment, 66(2), 217-233.

Wiggins, J. S., \& Holzmuller, A. (1981). Further evidence on androgyny and interpersonal flexibility. Journal of Research in Personality, 15, 67-80.

Winter, D. G. (1991). Measuring personality at a distance: Development of an integrated system for scoring motives in running text. In D. J. Ozer, J. M. Healy, Jr., \& A. J. Stewart (Eds.), Perspectives in personality, Vol. 3. Part A: Self and emotion; Part B: Approaches to understanding lives (p. 59-89). Jessica Kingsley Publishers.

Winter, D. G., John, O. P., Stewart, A. J., Klohnen, E. C., \& Duncan, L. E. (1998). Traits and motives: toward an integration of two traditions in personality research. Psychological Review, 105(2), 230-250.

Wispé, L. G. (1972). Positive forms of social behavior: An overview. Journal of Social Issues, 
$28,1-19$.

Wood, W., \& Eagly, A. H. (2015). Two traditions of research on gender identity. Sex Roles,

73(11-12), 461-473.

Wright, A. G., Pincus, A. L., \& Lenzenweger, M. F. (2012). Interpersonal development, stability, and change in early adulthood. Journal of Personality, 80(5), 1339-1372.

Zibenberg, A., \& Kupermintz, H. (2016). Personal values and intergroup empathy. Journal of Human Values, 22(3), 180-193. 


\section{Appendix}

\section{Considerations that Informed Our Definitions of Prosocial/Antisocial Behaviours.}

In defining prosocial and antisocial behaviours, we sought definitions that would: (1) capture the diversity of behaviours typically considered as prosocial/antisocial, (2) reflect common operationalizations in research, and (3) allow prosocial and antisocial definitions to mirror and complement each other (e.g., ensuring both or neither required an intent component). Relating to this final point, we note that alternative definitions require motivational/intentional states to underly the behaviours (e.g., selfless motives for prosocial behaviours, or desires to harm for antisocial behaviours; DeWall et al., 2012; Eisenberg \& Miller, 1987), but, following others (e.g., Buss, 1961; Loeber \& Hay, 1997), we omit such elements for three reasons.

First, many researchers and interventionists are interested in changing rates of behaviours regardless of the cognitions that prompt them. Correspondingly, most measures assess frequencies of prosocial/antisocial behaviours without assessing underlying cognitions (e.g., Rushton et al., 1981). When cognitions are assessed, they are usually used as predictors of behaviours (e.g., Greenslade \& White, 2005). Consequently, our definitions better align with current empirical research than definitions that incorporate such cognitions. Second, many prosocial and antisocial behaviours occur without deliberate intentions (e.g., habits and reflexive actions). Definitions requiring intentions would exclude these commonly studied behaviours. Third, our definitions allow us to avoid confounding behaviours with specific motivations, allowing us to study the full breath of motivations that underlie behaviour. For example, defining prosocial (antisocial) behaviours as requiring altruistic (hostile) motives would limit us to only studying cases when this is true. However, it is well documented that people can engage in prosocial behaviours for selfish reasons (Snyder \& Dwyer, 2012), and not just altruistic reasons. 
Similarly, people sometimes enact violence for altruistic reasons (e.g., in the defence of others;

Böhm et al., 2016) rather than because of inherent hostility.

Finally, we note that our definitions make no claim about the inherent morality of each

behaviour type, as each can vary in morality depending on contextual, sociocultural, and philosophical considerations. 


\section{Links Between Frameworks Delineating Self- and Other-Focused Orientations}

Table A1.

Works Documenting and Discussing Associations Between Each Framework, Along with Study 4 Correlations

\begin{tabular}{lcccccc}
\hline Framework & $\mathbf{1 .}$ & $\mathbf{2 .}$ & $\mathbf{3 .}$ & $\mathbf{4 .}$ & $\mathbf{5 .}$ & $\mathbf{6 .}$ \\
\hline 1. Interpersonal Circumplex & - & $\mathbf{A .}$ & $\mathbf{B .}$ & $\mathbf{C .}$ & $\mathbf{D .}$ & $\mathbf{E .}$ \\
2. Schwartz's Theory of Human Values & $.41 \mid .57$ & - & $\mathbf{F}$. & $\mathbf{G .}$ & $\mathbf{H .}$ & $\mathbf{I}$. \\
3. Masculinity | Femininity & - & - & - & $\mathbf{J .}$ & $\mathbf{K}$. & $\mathbf{L .}$ \\
4. Independence | Interdependence & $.51 \mid .29$ & $.63 \mid .63$ & - & - & $\mathbf{M}$. & $\mathbf{N}$. \\
5. Self- and Other-Interest & $.37 \mid .37$ & $.71 \mid .54$ & - & $.41 \mid .54$ & - & $\mathbf{O .}$ \\
6. Power, Achievement, Affiliation, & $.48, .54 \mid$ & $.47, .67 \mid$ & - & $.29, .56 \mid$ & $.65, .70 \mid$ & - \\
Intimacy & $.25, .48$ & $.39, .69$ & - & $.49, .55$ & $.58, .59$ & - \\
\hline
\end{tabular}

\section{References:}

A: Buchanan \& Bardi, 2015; Frimer et al., 2011; Milfont et al., 2016; Park-Leduc et al., 2015; Ponikiewska et al., 2020; Schwartz \& Bilsky, 1987; Trapnell \& Paulhus, 2012.

B: Bakan 1966; Bem et al., 1976; Helgeson, 1994; Hiller \& Philiber, 1985; Locke, 2000; Saragovi et al., 1997;

Trapnell \& Paulhus, 2012; Wiggins \& Holzmuller, 1981; Ward et al., 2006; Wood \& Eagly, 2015.

C: Abele \& Wojciszke, 2007; 2014; Abele et al., 2016; Miyamoto et al., 2018.

D: Abele \& Wojciszke, 2007; 2014; Frimer et al., 2011.

E: Brunstein et al., 1998, Mansfield \& McAdams, 1996; Pöhlmann, 2001; Schönbrodt \& Gerstenberg, 2012.

F: Di Dio et al., 1996; Schwartz \& Rubel, 2005; Schwartz \& Rubel-Lifschitz, 2009.

G: Cukur et al., 2004; Oishi et al., 1998; Schwartz, 1994b; Triandis et al., 1990; Verplanken et al., 2009

H: Gerbasi, 2011; Gerbasi \& Prentice, 2013; Schwartz et al., 2012b.

I: Bilsky \& Schwartz, 2008; Hofer et al., 2006; Schwartz, 2012; Schwartz et al., 2012b.

J: Cross \& Madson, 1997; Josephs et al., 1992; Kemmelmeier \& Oyserman, 2001.

K: Gerbasi, 2011; Gerbasi \& Prentice, 2013.

L: Diekman \& Eagly, 2008; James et al., 1995; Pöhlmann, 2001

M: Gerbasi, 2011; Gerbasi \& Prentice, 2013; Miyamoto et al., 2018.

$\mathbf{N}$ : Abele et al., 2016; Triandis et al., 1985

O: Abele \& Wojciszke, 2014; Gerbasi, 2011; Gerbasi \& Prentice, 2013.

Note. Letters in the upper diagonal indicate which references relate to each theoretical pairing. Numbers in the lower diagonal show correlations from Study 4. The first number in each cell (black italics; before the |) indicates the correlation between self-focused orientations (e.g.,

assertiveness and personal focus values $=.41$ ). The second number (grey, non-italics, after the $\mid$ ) indicates the correlation between other-focused orientations (e.g., compassion and social focus values $=.57$ ). Supplemental Table S28 provides a more detailed breakdown of correlations. 